\title{
Global solar radiation modeling using different machine learning and empirical models in Northeast China
}

\section{Yue Jia ( $\nabla$ jiayuescu@163.com )}

Hebei University of Water Resources and Electric Engineering

\section{Yongjun Su ( $\nabla 15130800077 @ 163 . c o m$ )}

Hebei university of water resources and electric engineering

Fengchun Wang ( $\square$ wangfengchun813@163.com )

Hebei university of water resources and electric engineering

Pengcheng Li

Hebei university of water resources and electric engineering

\section{Shuyi Huo}

Hebei university of water resources and electric engineering

\section{Research Article}

Keywords: Global solar radiation, Machine learning models, Empirical models, Sunshine duration

Posted Date: May 17th, 2021

DOI: https://doi.org/10.21203/rs.3.rs-422151/v1

License: (c) (i) This work is licensed under a Creative Commons Attribution 4.0 International License. Read Full License 


\section{Global solar radiation modeling using different machine learning and empirical models in Northeast China}

Yue Jia ${ }^{\mathrm{a}, \mathrm{b}}$, Yongjun Su ${ }^{\mathrm{a}, \mathrm{b}}$ *, Fengchun Wang a,b *, Pengcheng $\mathrm{Li}^{\mathrm{a}, \mathrm{b}}$, Shuyi Huo a,b

a. Hebei University of Water Resources and Electric Engineering \& Remote sensing and Smart water innovation Center, Cangzhou, 061001, China

b. Hebei University Center for Water Automation and Information Application Technology, Cangzhou, 061001, China

* Corresponding authors.

Email: 15130800077@163.com(Y.Su); wangfengchun813@163.com (F. Wang) 
1 Abstract: Reliable global solar radiation $\left(R_{\mathrm{s}}\right)$ information is crucial for the design and

2 management of solar energy systems for agricultural and industrial production.

3 However, $R_{\mathrm{s}}$ measurements are unavailable in many regions of the world, which

4 impedes the development and application of solar energy. To accurately estimate $R_{\mathrm{s}}$,

5 this study developed a novel machine learning model, called a Gaussian exponential

6 model (GEM), for daily global $R_{\mathrm{S}}$ estimation. The GEM was compared with four other

7 machine learning models and two empirical models to assess its applicability using

8 daily meteorological data from 1997-2016 from four stations in Northeast China. The

9 results showed that the GEM with complete inputs had the best performance. Machine

10 learning models provided better estimates than empirical models when trained by the

11 same input data. Sunshine duration was the most effective factor determining the

12 accuracy of the machine learning models. Overall, the GEM with complete inputs had

13 the highest accuracy and is recommended for modeling daily $R_{\mathrm{s}}$ in Northeast China.

14 Keywords: Global solar radiation; Machine learning models; Empirical models;

15 Sunshine duration 


\section{Declarations}

17 Ethics approval and consent to participate

$18 \quad$ Not applicable

19 Consent for publication

$20 \quad$ Not applicable

\section{Availability of data and materials}

22 The data that support the findings of this study are available from [National

23 Meteorological Science Data Centerhttps://data.CMA.cn/] but restrictions apply to the

24 availability of these data, which were used under license for the current study, and so

25 are not publicly available. Data are however available from the authors upon 26 reasonable request and with permission of [National Meteorological Science Data

27 Centerhttps://data.CMAcma.cn/].

\section{Competing interests}

29 The authors declare that they have no known competing financial interests or 30 personal relationships that could have appeared to influence the work reported in this 31 paper.

\section{$32 \quad$ Funding}

33 The research was funded by the Scientific Research Program of Higher Education 34 in Hebei Province (QN2021227) and the Water Conservancy Research and Extension 35 Project of Hebei Province(2020-64) and the Hebei Province Innovation Ability 36 Promotion Plan, Soft Science Research(20557682D), and the Colleges and 37 Universities in Hebei Province Science and Technology Research(ZD2020348) and 
38 the Doctoral Scientific Research Foundation of Hebei University of Water Resources 39 and Electric Engineering(SYBJ1902).

40 Authors' contributions

41 YJ analyzed and calculated the data and wrote the manuscript. YS and FW was

42 a major contributor in writing the manuscript and got the data of the manuscript. PL

43 calculated the data and made the tables of the manuscript. SH made the figures for the 44 manuscript. All authors read and approved the final manuscript. 


\section{Introduction}

Solar radiation $\left(R_{\mathrm{s}}\right)$ provides the essential energy for life on Earth (Wild et al., 2005) and is the foundation of global climate formation (Antonopoulos et al., 2019). Solar energy is one of the most advantageous energy sources, as it is clean, free, abundant, and inexhaustible (Khatib et al., 2012; Desideri et al., 2013; Jamil and Akhtar, 2017; Zhang et al., 2019). As the global energy demand is gradually increasing, solar energy has attracted increasing attention. The application of solar energy systems depends on the amount and intensity of global $R_{\mathrm{s}}$; thus, reliable information on $R_{\mathrm{s}}$ directly affects the development of solar energy (Citakoglu, 2015; Zhang et al., 2019). Furthermore, the level of $R_{\mathrm{s}}$ is directly related to the characteristics of regional climate change and the layout of agricultural production, especially crop production (Bailek et al., 2018; Chen et al., 2019; Fan et al., 2019). The most accurate $R_{\mathrm{s}}$ data can be obtained by measurements (Wu et al., 2019). However, the high requirements and costs of the measuring devices have resulted in few measurements worldwide (Besharat et al., 2013; Oates et al., 2017). China has the largest energy demand in the world. Among the 752 national meteorological stations in China, only 122 stations have measured $R_{\mathrm{s}}$ data (Pan et al., 2013). Thus, using other commonly available climatic data to predict $R_{\mathrm{S}}$ is a feasible alternative.

Various climatic variables, such as precipitation $(P)$, sunshine duration $(n)$, air temperature, and relative humidity $\left(H_{\mathrm{r}}\right)$, are effective factors for $R_{\mathrm{s}}$ estimation 

based on these climatic variables, including empirical models (Liu et al., 2009; Citakoglu, 2015; Demircan et al., 2020), machine learning models (Hossain et al., 2017; Fan et al., 2018), and radiative transfer models (Gueymard, 2001; Pawlak et al., 2004). Owing to the acceptable accuracy and low computational costs and input requirements, empirical models are the most widely applied models (Hassan et al., 2016), among which the Hargreaves-Samani (HS) model and Bristow-Campbell (BC) model are two well-known empirical models. Liu et al. (2009) modified the HS and $\mathrm{BC}$ models in different regions of China, and found that the accuracy of the models was improved by $4 \%-7 \%$ after correction.

Because $R_{\mathrm{s}}$ has a nonlinear relationship with other climatic variables, as indicated by empirical models, machine learning models can improve the accuracy of $R_{\mathrm{s}}$ estimation and prediction (Chen et al., 2011). To date, many machine learning models have been extensively applied to estimate and simulate $R_{\mathrm{S}}$ (Katiyar and Pandey, 2010; Jamil and Akhtar, 2017; Kaba et al., 2018; Feng et al., 2019a), such as the adaptive neuro-fuzzy inference system (ANFIS) (Tabari et al., 2012), M5 model tree (Kisi, 2016), and gene expression programming (Shiri et al., 2014). Bueno et al. (2019) evaluated the performances of neural networks, support vector regression, and Gaussian processes for $R_{\mathrm{s}}$ prediction using satellite data as inputs, and reported that the three machine learning models provided reliable estimates. Zou et al. (2017) compared the ANFIS 
model with an improved BC model and Yang's model for $R_{\mathrm{S}}$ estimation, and found that machine learning models showed better results than the BC model and Yang's model. Fan et al. (2019) compared 12 machine learning models and 12 empirical models to estimate $R_{\mathrm{s}}$. They showed that the ANFIS model, MARS model, and XGBoost model may be promising models in China.

\section{Day of year(DOY) is an important time parameter. Taking DOY as an input parameter} can comprehensively reflect the change rule of meteorological factors with time, and further improve the model accuracy(Zhu et al., 2019a). Gaussian exponential model(GEM) is a novel machine learning model that has not been applied to $R_{\mathrm{S}}$ estimation. China consumes a large amount of energy, and a significant amount of energy is used for economic development every year (Liu et al., 2017; Fan et al., 2018). Clean solar energy is of great significance for energy conservation and emission reduction (Jin et al., 2005; Feng et al., 2017a). Northeast China, which is the main industrial production region, accounts for approximately $20 \%$ of China's energy consumption (Zheng et al., 2019). Therefore, determining an optimal $R_{\mathrm{s}}$ model for this region can provide scientific information for solar energy applications. However, the performance of different models in this region has not been well documented. Thus, in this paper, DOY was added into the input parameter of machine learning models to estimate $R_{\mathrm{s}}$. GEM was developed to estimate $R_{\mathrm{s}}$ in Northeast China with different climate data. The main purpose of this study was to examine the applicability of five machine learning models (M5 model tree, support vector machine (SVM), random 
107 forest (RF) model, GEM, and boosted trees (BT) and two empirical models (HS and

$108 \mathrm{BC})$ for $R_{\mathrm{s}}$ prediction in Northeast China.

\section{Methods and materials}

\subsection{Study area and data collection}

111 Northeast China generally consists of three provinces and has a temperate monsoon

112 climate (Feng et al., 2018). In this study, long-term climatic data, including $R_{\mathrm{s}}, n$,

113 maximum and minimum air temperature ( $T_{\max }$ and $T_{\min }$, respectively), $H_{\mathrm{r}}$, wind speed

114 at $2 \mathrm{~m}$ height, and $P$, during 1997-2016 were collected from four stations located in

115 Northeast China (Fig. 1). Extra-terrestrial solar radiation $\left(R_{\mathrm{a}}\right)$ calculated from

116 geographic information and the day of the year (DOY) were also used for modeling.

117 These data were provided and quality examined by the China Meteorological

118 Administration. Figure 2 shows the monthly variations in climatic variables. Table 1

119 shows the climatic conditions of the study region.

\subsection{M5 model tree}

121 Quinlan (1992) first developed the M5 tree (M5T) model, which selects the expected

122 standard deviation after scanning all the possible splits (Wang et al., 1997; Feng et al.,

123 2019b). The procedure that makes up the model is divided into two parts. First, the

124 data are divided into several subsets to create decision trees. The expected error of the

125 subsets can be calculated by the model. The model accuracy can be defined as 126 follows: 


$$
S D R=S D(Q)-\sum \frac{\left|Q_{i}\right|}{|Q|} S D\left(Q_{i}\right)
$$

128 where $S D$ and $S D R$ are the standard deviations, $Q$ is a set of samples that reach the

129 target value, and $Q_{i}$ is a subset of $Q$.

130 To improve the application efficiency of the model, it is necessary to traverse each

131 node of the initial model tree through the pruning process to merge some subtrees and

132 replace them with leaf nodes (Sattari et al., 2013). The detailed model procedure of

133 the M5T model is described by Quinlan (1992).

\section{$134 \quad 2.3$ Support vector machine}

135 The SVM was first proposed by Vapnik (1999). This model is considered the best

136 theory for current small-sample statistical estimation and prediction learning (Belaid

137 et al., 2016; Shamshirband et al., 2016). The model replaces traditional experience

138 minimization with structural experience minimization, which can overcome many

139 shortcomings of neural networks (Quej et al., 2017). The SVM function can be

140 expressed as follows:

$$
f(x)=\sum_{i=1}^{n} \alpha_{i} y_{i} \kappa\left(x_{i}, x_{j}\right)+b
$$

142 where $\kappa\left(x_{i}, x_{j}\right)$ is a higher-dimensional feature vector converted from the input vector $x_{i}$

143 and $x_{j} \cdot y_{i}$ is the ordinate of the input vector, $\alpha_{i}$ is the weight of the input vector, and $b$

144 is the bias.

\subsection{Random forest model}

146 The RF model was proposed by Breiman (2001). The model introduces random 
147 attribute selection during model training. The model extracts data based on

148 randomness and difference, which can greatly improve decision accuracy. The

149 procedures of the RF model are described by Buja et al. (2008).

\subsection{Gaussian exponential model}

151 The GEM was proposed by Liu et al. (2014). The model is divided into three

152 procedures. First, learning samples are clustered by the k-means algorithm as the most

153 primitive allocation of samples. Second, the parameter estimates of the sample are

154 calculated using the maximum likelihood estimation. Third, learning samples are

155 regrouped according to the maximum posterior probability criterion. The model can

156 be defined as follows:

$$
f(n)=H_{i} \times \exp \left(-\frac{2\left(n-N_{i}\right)}{W_{i}^{2}}\right), i=1,2, \ldots n
$$

158 where $H_{i}$ is the peak amplitude, $N_{i}$ is the peak time position, and $W_{i}$ is the half-width

159 of the Gaussian wave.

\subsection{Boosted trees model}

161 The BT model was first proposed by Friedman (2001). The model is designed to

162 improve the performance of a single model by fitting multiple models while

163 combining them for prediction. The principle of model boosting is to promote a strong

164 combination through the input of weak learners. The BT model is divided into two

165 procedures, namely regression trees and boosting (Elias et al., 2016). The detailed

166 model procedure is described in the study by Friedman (2001). 
168 The HS model only uses $T_{\max }$ and $T_{\min }$ data as inputs and is widely reported to have

169 acceptable accuracy for $R_{\mathrm{s}}$ estimation. The model is as follows:

170

$$
R_{s}=\left[C\left(T_{\max }-T_{\min )}\right)^{0.5}\right] \times R_{a}
$$

171 where $R_{\mathrm{s}}$ is the global $R_{\mathrm{s}}\left(\mathrm{MJ} \cdot \mathrm{m}^{-2} \cdot \mathrm{d}^{-1}\right), T_{\max }$ and $T_{\min }$ are the $T_{\max }$ and $T_{\min }$, respectively

$172\left({ }^{\circ} \mathrm{C}\right), C$ is the empirical coefficient, and $R_{\mathrm{a}}$ is the $R_{\mathrm{a}}\left(\mathrm{MJ} \cdot \mathrm{m}^{-2} \cdot \mathrm{d}^{-1}\right)$.

173

\subsection{Bristow-Campbell model}

174 Bristow and Campbell (1984) developed the BC model, which only uses $R_{\mathrm{a}}$ and the

175 diurnal temperature range $(\triangle T)$ as the input data. The model is defined as follows:

$$
R_{s}=a\left[1-\exp \left(-b \Delta T^{c}\right)\right] \times R_{a}
$$

177 where $\triangle T$ is the $\Delta T\left({ }^{\circ} \mathrm{C}\right)$ and $a, b$, and $c$ are empirical coefficients.

\subsection{Model training and testing}

179 Five input combinations of meteorological data were used to train the machine

180 learning models. Details of the combinations are presented in Table 2. The dataset was

181 divided into two parts, i.e., 1997-2011 and 2012-2016, for training and testing the

182 machine learning models, respectively. The coefficients of the empirical models were

183 locally calibrated at each station by the least square error method using the training

184 data (data from 1997-2011). The model training/calibration and testing were

185 performed in Matlab 2018a. The parameters of the machine models are presented in

186 Table 3. 
188 The root mean square error (RMSE), relative root mean square error (RRMSE), 189 coefficient of determination $\left(R^{2}\right)$, mean absolute error (MAE), and coefficient of 190 efficiency $\left(E_{n s}\right)$ were used to assess the $R_{\mathrm{s}}$ models (Feng et al., 2017b), as follows:

$$
\mathrm{RMSE}=\sqrt{\frac{1}{m} \sum_{i=1}^{m}\left(Y_{i}-X_{i}\right)^{2}} \times 100 \%
$$

$$
\text { RRMSE }=\frac{\sqrt{\frac{1}{m} \sum_{i=1}^{m}\left(Y_{i}-X_{i}\right)^{2}}}{\bar{X}} \times 100 \%
$$

196 where $X_{i}$ and $Y_{i}$ are the trained and estimated values, respectively, and $\bar{X}$ is the

197 average value of $X_{i}$.

198 Owing to the excessive evaluation index, it is very difficult for a single evaluation

199 index to compare different models. Therefore, the global performance indicator (GPI)

200 was introduced to comprehensively evaluate the model simulation results (Despotovic

201 et al., 2015), as follows:

$$
G P I_{i}=\sum_{j=1}^{5} \alpha_{j}\left(g_{j}-y_{i j}\right)
$$

203 where $\alpha_{j}$ is a coefficient that is equal to 1 for the RMSE, RRMSE, and MAE and 204 equal to -1 for $E_{n s}$ and $R^{2} ; g_{j}$ represents the median of statistical indicator $j$, and $y_{i j}$ 
206 the better performance of the model.

\section{Results and discussion}

\subsubsection{Evaluation of the models on a daily basis}

210 The statistical performance of the models at the four stations is presented in Table 4.

211 At Harbin station, the BT1 model showed the highest accuracy under input scenario 1

212 with RMSE, RRMSE, $R^{2}, E_{n s}$, and MAE values of $2.893 \mathrm{MJ} \cdot \mathrm{m}^{-2} \cdot \mathrm{d}^{-1}, 36.1 \%, 0.569$,

2130.563 , and $3.742 \mathrm{MJ} \cdot \mathrm{m}^{-2} \cdot \mathrm{d}^{-1}$, respectively. Under input scenario 2, the BT2 model

214 showed the highest accuracy with RMSE, RRMSE, $R^{2}, E_{n s}$, and MAE values of 3.068

$215 \mathrm{MJ} \cdot \mathrm{m}^{-2} \cdot \mathrm{d}^{-1}, 22.6 \%, 0.842,0.828$, and $2.305 \mathrm{MJ} \cdot \mathrm{m}^{-2} \cdot \mathrm{d}^{-1}$, respectively. Under input

216 scenario 3, the five machine learning models had higher accuracies than the models

217 under input scenarios 1 and 2, with an RMSE value of less than $2.900 \mathrm{MJ} \cdot \mathrm{m}^{-2} \cdot \mathrm{d}^{-1}$,

218 RRMSE value of less than $21.4 \%, R^{2}$ value of greater than $0.952, E_{n s}$ value of greater

219 than 0.931 , and MAE of less than $2.237 \mathrm{MJ} \cdot \mathrm{m}^{-2} \cdot \mathrm{d}^{-1}$. This indicated that introducing

220 climatic variables into the model training greatly improved the model performance.

221 Among the models under input scenario 3, the BT3 model had the highest accuracy 222 with RMSE, RRMSE, $R^{2}, E_{n s}$, and MAE values of $1.944 \mathrm{MJ} \cdot \mathrm{m}^{-2} \cdot \mathrm{d}^{-1}, 15.4 \%, 0.952$, 223 0.931, and $1.456 \mathrm{MJ} \cdot \mathrm{m}^{-2} \cdot \mathrm{d}^{-1}$, respectively. The BT4 model showed the highest 224 accuracy under input scenario 4 with RMSE, RRMSE, $R^{2}, E_{n s}$, and MAE values of 
226 input scenario 5, the GEM5 showed the highest accuracy with RMSE, RRMSE, $R^{2}$, $227 E_{n s}$, and MAE values of $1.719 \mathrm{MJ} \cdot \mathrm{m}^{-2} \cdot \mathrm{d}^{-1}, 12.7 \%, 0.964,0.946$, and $1.283 \mathrm{MJ} \cdot \mathrm{m}^{-2} \cdot \mathrm{d}^{-1}$, 228 respectively.

229 At Jilin station, the BT1 model showed the highest accuracy under input scenario 1 230 with RMSE, RRMSE, $R^{2}, E_{n s}$, and MAE values of $5.393 \mathrm{MJ} \cdot \mathrm{m}^{-2} \cdot \mathrm{d}^{-1}, 43.6 \%, 0.503$, 2310.501 , and $4.030 \mathrm{MJ} \cdot \mathrm{m}^{-2} \cdot \mathrm{d}^{-1}$, respectively. Under input scenario 2 , the BT2 model 232 showed the highest accuracy with RMSE, RRMSE, $R^{2}, E_{n s}$, and MAE values of 3.157 $233 \mathrm{MJ} \cdot \mathrm{m}^{-2} \cdot \mathrm{d}^{-1}, 23.2 \%, 0.835,0.829$, and $2.211 \mathrm{MJ} \cdot \mathrm{m}^{-2} \cdot \mathrm{d}^{-1}$, respectively. Under input 234 scenario 3, the BT3 model had the highest accuracy with RMSE, RRMSE, $R^{2}, E_{n s}$, 235 and MAE values of $1.513 \mathrm{MJ} \cdot \mathrm{m}^{-2} \cdot \mathrm{d}^{-1}, 11.1 \%, 0.961,0.961$, and $1.013 \mathrm{MJ} \cdot \mathrm{m}^{-2} \cdot \mathrm{d}^{-1}$, 236 respectively. Under input scenario 4, the BT4 model showed the highest accuracy. The 237 five machine learning models under input scenario 5 showed the highest accuracies 238 among the models under different input scenarios. The GEM5 showed the highest 239 accuracy with RMSE, RRMSE, $R^{2}, E_{n s}$, and MAE values of $1.245 \mathrm{MJ} \cdot \mathrm{m}^{-2} \cdot \mathrm{d}^{-1}, 9.1 \%$, $240 \quad 0.974,0.973$, and $0.844 \mathrm{MJ} \cdot \mathrm{m}^{-2} \cdot \mathrm{d}^{-1}$, respectively.

241 At Shenyang station, the BT1 model showed the highest accuracy under input 242 scenario 1 with RMSE, RRMSE, $R^{2}, E_{n s}$, and MAE values of $5.355 \mathrm{MJ} \cdot \mathrm{m}^{-2} \cdot \mathrm{d}^{-1}, 37.7 \%$, $2430.503,0.489$, and $4.265 \mathrm{MJ} \cdot \mathrm{m}^{-2} \cdot \mathrm{d}^{-1}$, respectively. Under input scenario 2 , the BT2 244 model showed the highest accuracy with RMSE, RRMSE, $R^{2}, E_{n s}$, and MAE values of 
245

3.227 MJ $\cdot \mathrm{m}^{-2} \cdot \mathrm{d}^{-1}, 22.7 \%, 0.822,0.814$, and $2.412 \mathrm{MJ} \cdot \mathrm{m}^{-2} \cdot \mathrm{d}^{-1}$, respectively. Under input scenario 3, all the machine learning models had higher accuracies than the models under input scenarios 1 and 2, with an RMSE value of less than 2.619 $\mathrm{MJ} \cdot \mathrm{m}^{-2} \cdot \mathrm{d}^{-1}$, RRMSE of less than $18.4 \%, R^{2}$ of over $0.882, E_{n s}$ of over 0.878 , and MAE of less than $1.836 \mathrm{MJ} \cdot \mathrm{m}^{-2} \cdot \mathrm{d}^{-1}$. The BT3 model had the highest accuracy with RMSE, RRMSE, $R^{2}, E_{n s}$, and MAE values of $1.876 \mathrm{MJ} \cdot \mathrm{m}^{-2} \cdot \mathrm{d}^{-1}, 13.2 \%, 0.940,0.937$, and 1.299 MJ $\cdot \mathrm{m}^{-2} \cdot \mathrm{d}^{-1}$, respectively. The BT4 model showed the highest accuracy under input scenario 4 with RMSE, RRMSE, $R^{2}, E_{n s}$, and MAE values of 2.010 $\mathrm{MJ} \cdot \mathrm{m}^{-2} \cdot \mathrm{d}^{-1}, 14.1 \%, 0.930,0.928$, and $1.407 \mathrm{MJ} \cdot \mathrm{m}^{-2} \cdot \mathrm{d}^{-1}$, respectively. Under input scenario 5, the GEM5 showed the highest accuracy with RMSE, RRMSE, $R^{2}, E_{n s}$, and MAE values of $1.658 \mathrm{MJ} \cdot \mathrm{m}^{-2} \cdot \mathrm{d}^{-1}, 11.7 \%, 0.953,0.951$, and $1.147 \mathrm{MJ} \cdot \mathrm{m}^{-2} \cdot \mathrm{d}^{-1}$, respectively.

At Yanji station, the BT1 model showed the highest accuracy under input scenario 1 with RMSE, RRMSE, $R^{2}, E_{n s}$, and MAE values of $5.030 \mathrm{MJ} \cdot \mathrm{m}^{-2} \cdot \mathrm{d}^{-1}, 36.6 \%, 0.484$, 0.476, and 3.973 $\mathrm{MJ} \cdot \mathrm{m}^{-2} \cdot \mathrm{d}^{-1}$, respectively. Under input scenario 2, the BT2 model showed the highest accuracy with RMSE, RRMSE, $R^{2}, E_{n s}$, and MAE values of 2.809 $\mathrm{MJ} \cdot \mathrm{m}^{-2} \cdot \mathrm{d}^{-1}, 20.4 \%, 0.849,0.837$, and $2.194 \mathrm{MJ} \cdot \mathrm{m}^{-2} \cdot \mathrm{d}^{-1}$, respectively. Under input scenario 3, the five models had higher accuracies than the models under input scenarios 1 and 2, with an RMSE of less than $1.746 \mathrm{MJ} \cdot \mathrm{m}^{-2} \cdot \mathrm{d}^{-1}$, RRMSE of less than $12.7 \%, R^{2}$ of over $0.946, E_{n s}$ of over 0.937 , and MAE of less than $1.322 \mathrm{MJ} \cdot \mathrm{m}^{-2} \cdot \mathrm{d}^{-1}$. The BT3 model had the highest accuracy with RMSE, RRMSE, $R^{2}, E_{n s}$, and MAE 
values of $1.226 \mathrm{MJ} \cdot \mathrm{m}^{-2} \cdot \mathrm{d}^{-1}, 8.9 \%, 0.973,0.969$, and $0.943 \mathrm{MJ} \cdot \mathrm{m}^{-2} \cdot \mathrm{d}^{-1}$, respectively.

267 The BT4 model showed the highest accuracy under input scenario 4 with RMSE, 268 RRMSE, $R^{2}, E_{n s}$, and MAE values of $1.259 \mathrm{MJ} \cdot \mathrm{m}^{-2} \cdot \mathrm{d}^{-1}, 9.2 \%, 0.971,0.967$, and 0.970

$269 \mathrm{MJ} \cdot \mathrm{m}^{-2} \cdot \mathrm{d}^{-1}$, respectively. Under input scenario 5 , the GEM5 showed the highest 270 accuracy with RMSE, RRMSE, $R^{2}, E_{n s}$, and MAE values of $1.045 \mathrm{MJ} \cdot \mathrm{m}^{-2} \cdot \mathrm{d}^{-1}, 7.6 \%$, $2710.981,0.977$, and $0.801 \mathrm{MJ} \cdot \mathrm{m}^{-2} \cdot \mathrm{d}^{-1}$, respectively.

272 As for the empirical models, the HS and BC models showed lower accuracies 273 compared with those of the machine learning models with the same inputs (input 274 scenario 3), with an RMSE of 3.885-4.557 MJ $\cdot \mathrm{m}^{-2} \cdot \mathrm{d}^{-1}, R^{2}$ of $0.634-0.707$, RRMSE of $27528.3 \%-32.2 \%$, Ens of $0.630-0.696$, and MAE of $3.069-3.526 \mathrm{MJ} \cdot \mathrm{m}^{-2} \cdot \mathrm{d}^{-1}$. The 276 accuracy of the machine learning models considering $n$ was significantly higher than 277 that of the models without $n$ input, with the RMSE reduced by $44.3 \%-79.9 \%$, 278 RRMSE reduced by $44.2 \%-91.2 \%$, MAE reduced by $40.2 \%-80.6 \%, R^{2}$ increased by $27967.7 \%-95.6 \%$, and $E_{n s}$ increased by $67.4 \%-124.9 \%$.

280 The Boxplots of the statistical indicators of daily $R_{\mathrm{s}}$ for different models in the study 281 area are presented in Fig. 3. Under input scenario 1, the five machine learning models 282 showed low prediction accuracies for the whole region, with average RMSE, RRMSE, 283 MAE, and $E_{n s}$ values of $4.668-9.627 \mathrm{MJ} \cdot \mathrm{m}^{-2} \cdot \mathrm{d}^{-1}, 38.8 \%-69.9 \%, 4.002-7.579$ $284 \mathrm{MJ} \cdot \mathrm{m}^{-2} \cdot \mathrm{d}^{-1}$, and $0.220-0.507$, respectively. The BT1 model showed the highest 285 accuracy among the five models. Under input scenario 2, the BT2 model was the best 
model with average RMSE, RRMSE, MAE, and $E_{n s}$ values of $3.065 \mathrm{MJ} \cdot \mathrm{m}^{-2} \cdot \mathrm{d}^{-1}$, $22.2 \%, 2.281 \mathrm{MJ} \cdot \mathrm{m}^{-2} \cdot \mathrm{d}^{-1}$, and 0.827 , respectively. The five models under input scenario 3 showed higher prediction accuracies than the models under input scenarios 1 and 2, which did not consider climatic variables as inputs. The BT3 model showed the best results with average RMSE, RRMSE, MAE, and $E_{n s}$ values of 1.639 $\mathrm{MJ} \cdot \mathrm{m}^{-2} \cdot \mathrm{d}^{-1}, 12.2 \%, 1.178 \mathrm{MJ} \cdot \mathrm{m}^{-2} \cdot \mathrm{d}^{-1}$, and 0.950 , respectively. Under input scenario 4 , the BT4 model showed the highest accuracy with average RMSE, RRMSE, MAE, and $E_{n s}$ values of $1.711 \mathrm{MJ} \cdot \mathrm{m}^{-2} \cdot \mathrm{d}^{-1}, 12.4 \%, 1.243 \mathrm{MJ} \cdot \mathrm{m}^{-2} \cdot \mathrm{d}^{-1}$, and 0.945 , respectively. Under input scenario 5, the GEM5 showed the highest accuracy with average RMSE, RRMSE, MAE, and $E_{n s}$ values of $1.417 \mathrm{MJ} \cdot \mathrm{m}^{-2} \cdot \mathrm{d}^{-1}, 10.26 \%, 1.019 \mathrm{MJ} \cdot \mathrm{m}^{-2} \cdot \mathrm{d}^{-1}$, and 0.962, respectively. The HS and BC models showed much lower prediction accuracies compared with those of the machine learning models, with average RMSE, RRMSE, MAE, and $E_{n s}$ values of $4.306 \mathrm{MJ} \cdot \mathrm{m}^{-2} \cdot \mathrm{d}^{-1}$ and $4.174 \mathrm{MJ} \cdot \mathrm{m}^{-2} \cdot \mathrm{d}^{-1}, 31.23 \%$ and $30.26 \%$, $3.341 \mathrm{MJ} \cdot \mathrm{m}^{-2} \cdot \mathrm{d}^{-1}$ and $3.218 \mathrm{MJ} \cdot \mathrm{m}^{-2} \cdot \mathrm{d}^{-1}$, and 0.658 and 0.679 , respectively.

The GPI values of the different models at the four stations are presented in Fig. 4. The SVM1, M5T1, GEM1, RF1, and BT1 models under input scenario 1 showed the lowest prediction accuracies compared with those of models under other input scenarios, with average GPI values of $-3.915,-3.101,-2.883,-3.357$, and -2.163 , respectively. Under input scenario 2, the BT2 model showed the highest overall accuracy, followed by the GEM2, SVM2, RF2, and M5T2 models with average GPI values of $-0.569,-0.852,-1.131,-1.478$, and -1.599 , respectively. Under input 
scenario 3, the BT3 model showed the highest accuracy, followed by the GEM3,

308 SVM3, RF3, and M5T3 models with average GPI values of $0.485,0.399,0.193$,

3090.034 , and -0.040 , respectively. The BT4 model was the best model under input

310 scenario 4, followed by the GEM4, RF4, M5T4, and SVM4 models with average GPI

311 values of $0.434,0.375,0.033,0.019$, and -0.211 , respectively. Under input scenario 5,

312 the GEM5 and BT5 models showed much higher accuracies with average GPI values

313 of 0.641 and 0.560 , respectively. The accuracies of the HS and BC models were

314 higher than those of the M5T1, SVM1, GEM1, RF1, and BT1 models without

315 climatic inputs, with average GPI values of -1.745 and -1.622 , respectively. Relatively

316 good estimates and high accuracies could be obtained from models with at least the

317 DOY, $R_{\mathrm{a}}$, and $n$ as inputs, including models under input scenarios 3 , 4, and 5 . These

318 results further confirm that $n$ is the most important variable for estimating $R_{\mathrm{s}}$.

\subsubsection{Evaluation of the models on a monthly basis}

320 The accuracy index of monthly $R_{\mathrm{S}}$ of different models in different stations is

321 presented in Table.5. As shown in Table.5, in Harbin station, the BT1 model showed

322 the highest accuracy under input scenario1, with RMSE of $0.878 \mathrm{MJ} \mathrm{m}^{-2} \mathrm{~d}^{-1}$, RRMSE

323 of $13.5 \%, \mathrm{R}^{2}$ of $0.984, \mathrm{E}_{\mathrm{ns}}$ of $0.943, \mathrm{MAE}$ of $0.803 \mathrm{MJ} \mathrm{m}^{-2} \mathrm{~d}^{-1}$. Under input scenario2,

324 the BT2 model showed the highest accuracy, followed by the GEM2 model, with

325 RMSE of 0.692 and $0.814 \mathrm{MJ} \mathrm{m}^{-2} \mathrm{~d}^{-1}$, RRMSE of $11.1 \%$ and $11 \%, \mathrm{R}^{2}$ of 0.997 and

$3260.996, E_{n s}$ of 0.953 and 0.937, MAE of 0.702 and $1.371 \mathrm{MJ} \mathrm{m}^{-2} \mathrm{~d}^{-1}$. Under input

327 scenario3, the five models had higher accuracy than the models under input scenario1 
328

330

332

334

and scenario2, with RMSE less than $0.825 \mathrm{MJ} \mathrm{m}^{-2} \mathrm{~d}^{-1}$, RRMSE less than $8.5 \%$, $\mathrm{R}^{2}$ over than 0.999, Ens over than 0.972, MAE less than $0.621 \mathrm{MJ} \mathrm{m}^{-2} \mathrm{~d}^{-1}$. BT3 model had the highest accuracy with RMSE of $0.601 \mathrm{MJ} \mathrm{m}^{-2} \mathrm{~d}^{-1}$, RRMSE of $7.5 \%, \mathrm{R}^{2}$ of 1.000 , Ens of 0.984, MAE of $0.467 \mathrm{MJ} \mathrm{m}^{-2} \mathrm{~d}^{-1}$. BT4 model showed the best precision under input scenario4, with RMSE of $0.506 \mathrm{MJ} \mathrm{m}^{-2} \mathrm{~d}^{-1}$, RRMSE of $7.2 \%, \mathrm{R}^{2}$ of 0.999 , Ens of 0.987, MAE of $0.463 \mathrm{MJ} \mathrm{m}^{-2} \mathrm{~d}^{-1}$. Under input scenario5, GEM5 model and BT5 model showed much higher accuracy among the five models, with RMSE of 0.575 and $0.456 \mathrm{MJ} \mathrm{m}^{-2} \mathrm{~d}^{-1}, \mathrm{RRMSE}$ of $7.0 \%$ and $7.1 \%, \mathrm{R}^{2}$ of 1.000 and 1.000 , Ens of 0.989 and 0.988 , MAE of 0.499 and $0.411 \mathrm{MJ} \mathrm{m}^{-2} \mathrm{~d}^{-1}$. HS model and BC model showed much poorer prediction accuracy with RMSE of 1.186 and $1.193 \mathrm{MJ} \mathrm{m}^{-2} \mathrm{~d}^{-1}$, with RRMSE of $8.8 \%$ and $8.8 \%, \mathrm{R}^{2}$ of 0.977 and 0.976 , MAE of 0.955 and $0.951 \mathrm{MJ} \mathrm{m}^{-2}$ $\mathrm{d}^{-1}$, Ens of 0.951 and 0.950 , respectively.

In Jilin station, the BT1 model showed the highest accuracy under input scenario1, with RMSE of $0.932 \mathrm{MJ} \mathrm{m}^{-2} \mathrm{~d}^{-1}$, RRMSE of $6.6 \%, \mathrm{R}^{2}$ of 0.971 , Ens of 0.964 , MAE of $0.750 \mathrm{MJ} \mathrm{m}^{-2} \mathrm{~d}^{-1}$. Under input scenario2, the BT2 model had the best precision, with RMSE of $0.525 \mathrm{MJ} \mathrm{m}^{-2} \mathrm{~d}^{-1}$, RRMSE of $2.4 \%, \mathrm{R}^{2}$ of 0.907, Ens of 0.926 , MAE of $0.261 \mathrm{MJ} \mathrm{m}^{-2} \mathrm{~d}^{-1}$. Under input scenario3, the BT3 model had the highest accuracy with RMSE of $0.256 \mathrm{MJ} \mathrm{m}^{-2} \mathrm{~d}^{-1}$, RRMSE of $1.9 \%, \mathrm{R}^{2}$ of 0.998 , Ens of 0.998 , MAE of $0.176 \mathrm{MJ} \mathrm{m}^{-2} \mathrm{~d}^{-1}$. Under input scenario4, the BT4 model showed the best precision, with RMSE of $0.341 \mathrm{MJ} \mathrm{m}^{-2} \mathrm{~d}^{-1}$, RRMSE of $2.8 \%, \mathrm{R}^{2}$ of $0.998, \mathrm{E}_{\text {ns }}$ of 0.994 , MAE of $0.301 \mathrm{MJ} \mathrm{m}^{-2} \mathrm{~d}^{-1}$. The five models under the input scenario5 showed the highest 

accuracy, followed by the BT5 model, with RMSE of 0.197 and $0.242 \mathrm{MJ} \mathrm{m}^{-2} \mathrm{~d}^{-1}$, RRMSE of $1.5 \%$ and $1.8 \%, \mathrm{R}^{2}$ of 0.999 and 0.998 , Ens of 0.999 and 0.998, MAE of accuracy with RMSE of 0.672 and $0.643 \mathrm{MJ} \mathrm{m}^{-2} \mathrm{~d}^{-1}$, with RRMSE of 5.4\% and 4.7\%, respectively. accuracy, followed by GEM1 model, with RMSE of 0.932 and $0.962 \mathrm{MJ} \mathrm{m}^{-2} \mathrm{~d}^{-1}$,

358 RRMSE of $6.6 \%$ and $6.8 \%, \mathrm{R}^{2}$ of 0.971 and 0.979 , Ens of 0.964 and 0.962 , MAE of 0.750 and $0.788 \mathrm{MJ} \mathrm{m}^{-2} \mathrm{~d}^{-1}$. Under input scenario2, BT2 model showed the best 360 precision, with RMSE of $0.579 \mathrm{MJ} \mathrm{m}^{-2} \mathrm{~d}^{-1}$, RRMSE of $4.7 \%, \mathrm{R}^{2}$ of 0.986 , Ens of 0.984 , 361 MAE of $0.496 \mathrm{MJ} \mathrm{m}^{-2} \mathrm{~d}^{-1}$. Under input scenario3, the five models had higher accuracy 362 than the models under input scenario1 and scenario2, with RMSE less than 0.617 MJ $363 \mathrm{~m}^{-2} \mathrm{~d}^{-1}$, RRMSE less than $4.3 \%, \mathrm{R}^{2}$ over than 0.995 , Ens over than 0.984 , MAE less 364 than $0.513 \mathrm{MJ} \mathrm{m}^{-2} \mathrm{~d}^{-1}$. GEM3 model and BT3 model showed higher accuracy with 365 RMSE of 0.347 and $0.340 \mathrm{MJ} \mathrm{m}^{-2} \mathrm{~d}^{-1}$, RRMSE of $2.4 \%$ and $2.4 \%, \mathrm{R}^{2}$ of 0.999 and 366 0.999, Ens of 0.995 and 0.995, MAE of 0.268 and $0.276 \mathrm{MJ} \mathrm{m}^{-2} \mathrm{~d}^{-1}$. BT4 model, 367 GEM4 model and SVM4 model showed better precision under input scenario4, with 368 RMSE of $0.341,0.320$ and $0.398 \mathrm{MJ} \mathrm{m}^{-2} \mathrm{~d}^{-1}$, RRMSE of $2.8 \%, 3.0 \%$ and $3.0 \%, \mathrm{R}^{2}$ of $3690.998,0.998$ and $0.996, E_{n s}$ of $0.994,0.995$ and 0.993, MAE of $0.301,0.293$ and 
370

371

$0.309 \mathrm{MJ} \mathrm{m}^{-2} \mathrm{~d}^{-1}$, respectively. Under input scenario5, GEM5 model showed the highest accuracy, followed by BT5 model, with RMSE of 0.313 and $0.351 \mathrm{MJ} \mathrm{m}^{-2} \mathrm{~d}^{-1}$, RRMSE of $2.2 \%$ and $2.5 \%, \mathrm{R}^{2}$ of 0.999 and 0.998 , Ens of 0.996 and 0.995 , MAE of 0.256 and $0.273 \mathrm{MJ} \mathrm{m}^{-2} \mathrm{~d}^{-1}$, respectively. HS model and $\mathrm{BC}$ model showed much poorer prediction accuracy with RMSE of 0.856 and $0.962 \mathrm{MJ} \mathrm{m}^{-2} \mathrm{~d}^{-1}$, with RRMSE of $6.0 \%$ and $6.8 \%, \mathrm{R}^{2}$ of 0.939 and $0.926, \mathrm{MAE}$ of 0.680 and $0.790 \mathrm{MJ} \mathrm{m}^{-2} \mathrm{~d}^{-1}, \mathrm{E}_{\text {ns }}$ of 0.970 and 0.962 , respectively.

In Yanji station, the BT1 model showed the highest accuracy under input scenario1, with RMSE of $0.795 \mathrm{MJ} \mathrm{m}^{-2} \mathrm{~d}^{-1}$, RRMSE of $8.1 \%, \mathrm{R}^{2}$ of $0.991, \mathrm{E}_{\text {ns }}$ of 0.977 , MAE of $0.627 \mathrm{MJ} \mathrm{m}^{-2} \mathrm{~d}^{-1}$. Under input scenario2, the BT2 model showed the highest accuracy, with RMSE of $0.661 \mathrm{MJ} \mathrm{m}^{-2} \mathrm{~d}^{-1}$, RRMSE of $4.8 \%, \mathrm{R}^{2}$ of $0.998, \mathrm{E}_{\text {ns }}$ of 0.979 , MAE of $0.603 \mathrm{MJ} \mathrm{m}^{-2} \mathrm{~d}^{-1}$. Under input scenario3, the five models had higher accuracy than the models under input scenario1 and scenario2, with RMSE less than $0.694 \mathrm{MJ} \mathrm{m}^{-2} \mathrm{~d}^{-1}$, RRMSE less than $5.4 \%, \mathrm{R}^{2}$ over than 0.998 , Ens over than 0.974, MAE less than 0.649 MJ m ${ }^{-2} \mathrm{~d}^{-1}$. BT3 model had the highest accuracy with RMSE of $0.455 \mathrm{MJ} \mathrm{m}^{-2} \mathrm{~d}^{-1}$, RRMSE of $3.6 \%, \mathrm{R}^{2}$ of $0.999, \mathrm{E}_{\mathrm{ns}}$ of $0.991, \mathrm{MAE}$ of $0.408 \mathrm{MJ} \mathrm{m}^{-2} \mathrm{~d}^{-1}$. BT4 model showed the best precision under input scenario4, with RMSE of $0.454 \mathrm{MJ} \mathrm{m}^{-2} \mathrm{~d}^{-1}$, RRMSE of $3.3 \%, \mathrm{R}^{2}$ of 0.999 , Ens of 0.992 , MAE of $0.409 \mathrm{MJ} \mathrm{m}^{-2} \mathrm{~d}^{-1}$. Under input scenario5, the GEM5 model showed the highest accuracy, followed by the BT5 model, with RMSE of 0.463 and $0.447 \mathrm{MJ} \mathrm{m}^{-2} \mathrm{~d}^{-1}$, RRMSE of $3.0 \%$ and $3.3 \%, \mathrm{R}^{2}$ of 1.000 and $0.999, E_{n s}$ of 0.992 and 0.992, MAE of 0.384 and $0.407 \mathrm{MJ} \mathrm{m}^{-2} \mathrm{~d}^{-1}$.HS model and 

and $1.092 \mathrm{MJ} \mathrm{m}^{-2} \mathrm{~d}^{-1}$, Ens of 0.917 and 0.926 , respectively.

394 The Boxplots of the statistical indicators of monthly $R_{\mathrm{s}}$ for different models in the 395 study area are presented in Fig.5. Under input scenario1, the five models showed 396 lower prediction accuracy in the whole studied area, with RMSE of 0.824-1.308 MJ $397 \mathrm{~m}^{-2} \mathrm{~d}^{-1}$, with RRMSE of $8.0 \%-10.3 \%$, MAE of $0.636-1.077 \mathrm{MJ} \mathrm{m}^{-2} \mathrm{~d}^{-1}, \mathrm{E}_{\mathrm{ns}}$ of 398 0.898-0.944. BT1 model showed the highest accuracy among the five models. Under 399 input scenario2, the BT2 model was the best model with RMSE of $0.614 \mathrm{MJ} \mathrm{m}^{-2} \mathrm{~d}^{-1}$, 400 with RRMSE of $5.7 \%$, MAE of $0.515 \mathrm{MJ} \mathrm{m}^{-2} \mathrm{~d}^{-1}, \mathrm{E}_{\mathrm{ns}}$ of 0.961 . The five models under 401 the input scenario3 showed higher prediction accuracy than the models under the 402 input scenario1-2. The BT3 model showed the best precision, followed by the GEM3 403 model, with RMSE of 0.413 and $0.433 \mathrm{MJ} \mathrm{m}^{-2} \mathrm{~d}^{-1}$, with RRMSE of $3.85 \%$ and $3.8 \%$, 404 MAE of 0.331 and $0.365 \mathrm{MJ} \mathrm{m}^{-2} \mathrm{~d}^{-1}$, Ens of 0.992and 0.989. Under input scenario4, 405 the BT4 model showed the highest accuracy with RMSE of $0.387 \mathrm{MJ} \mathrm{m}^{-2} \mathrm{~d}^{-1}$, with 406 RRMSE of $3.8 \%$, MAE of $0.334 \mathrm{MJ} \mathrm{m}^{-2} \mathrm{~d}^{-1}, \mathrm{E}_{\mathrm{ns}}$ of 0.993 . Under input scenario5, the 407 BT5 model and GEM5 model showed higher accuracy, with RMSE of 0.374 and $4080.387 \mathrm{MJ} \mathrm{m}^{-2} \mathrm{~d}^{-1}$, with RRMSE of $3.7 \%$ and $3.8 \%$, MAE of 0.312 and $0.319 \mathrm{MJ} \mathrm{m}^{-2}$ $409 \mathrm{~d}^{-1}$, Ens of 0.993 and 0.994 . HS model and BC model showed much poorer prediction 410 accuracy with RMSE of 1.005 and $1.009 \mathrm{MJ} \mathrm{m}^{-2} \mathrm{~d}^{-1}$, with RRMSE of $7.3 \%$ and $7.4 \%$, 411 MAE of 0.822 and $0.848 \mathrm{MJ} \mathrm{m}^{-2} \mathrm{~d}^{-1}$, Ens of 0.952 and 0.955 , respectively. 
413 Fig.6. As shown in Fig.6, SVM1, MET1, RF1, GEM1 and BT1 models under input 414 scenario1 showed the lowest prediction accuracy, with average GPI of $-2.957,-2.406$, $415-1.979,-1.553$ and -1.034 respectively. Under input scenario2, the BT2 model showed 416 the highest accuracy, followed by the GEM2 model, SVM2 model, RF2 model, M5T2 417 model, with average GPI of $-0.182,-0.648,-0.965,-1.172$ and -1.381 respectively. 418 Under input scenario3, the BT3 model showed the best precision, followed by the 419 GEM3 model, SVM3 model, RF3 model, M5T3 model, with average GPI of 0.730, 420 0.654, 0.450, 0.112 and 0.076 . The BT4 model was the best model under input 421 scenario4, followed by the GEM4 model, SVM4 model, RF4 model, M5T4 model, 422 with average GPI of $0.755,0.686,0.403,0.120$ and 0.077 . Under input scenario5, the 423 GEM5 model showed the best precision, followed by the BT5 model, SVM5 model, 424 RF5 model, M5T5 model, with average GPI of $0.855,0.809,0.566,0.166$ and 0.121. 425 The accuracy of HS and BC models was high than M5T1, SVM1 and RF1 models, 426 with average GPI of -1.734 and -1.742 respectively. Machine learning models with 427 complete data inputs had the highest precision. Meanwhile, the models which 428 considered $n, T_{\max }$ and $T_{\min }, n$ and $\mathrm{P}$ showed similar precision compared the models as 429 for seven-inputs. The models only considered DOY and Ra showed the lowest 430 prediction accuracy, with GPI of $-4.114--0.588$. The accuracy of the monthly $R_{\mathrm{s}}$ 431 models which considered DOY, Ra, $T_{\max }$ and $T_{\min }$ were higher than the models for two 432 inputs, with GPI increased by $17.5 \%-29.4 \%$. The increase in accuracy was not 
433

434

significant. In the calculation of monthly $R_{\mathrm{s}}$, sunshine duration were the most significant variables in the studied area.

\subsection{Discussion}

Machine learning models generally had a higher accuracy than the HS and BC models when climatic variables were included as inputs. The machine learning models that considered only the DOY and $R_{\mathrm{a}}$ showed the lowest accuracies at the four stations, especially the SVM1 and RF1 models. Fan et al. (2019) showed that in China, the SVM and RF models had worse rankings, which agrees with our conclusion. The GEM and BT models had higher accuracies than other machine learning models when the same inputs were applied. The BT model was found to be the best model under input scenarios 1, 2, 3, and 4. It is an information-theoretical discriminative predictor which can boost an information-theoretical discriminative predictor (Israeli et al., 2019). Persson et al. (2017) analyzed the accuracy of the BT model for $R_{\mathrm{s}}$ estimation in Japan, and reported that the BT model had the highest accuracy with an RMSE of between $0.100 \mathrm{MJ} \cdot \mathrm{m}^{-2} \cdot \mathrm{d}^{-1}$ and $0.137 \mathrm{MJ} \cdot \mathrm{m}^{-2} \cdot \mathrm{d}^{-1}$. However, under the full climatic input scenario (input scenario 5), the GEM provided the best estimates. Through the statistical analysis of big data, the GEM estimation could be obtained by comprehensively analyzing the relationship between the measured data and the model access data (Lesser et al., 2011). This may be the reason for the high accuracy of the GEM. Although the BT model and GEM showed alternate rankings under different input scenarios, the differences were small. 

different models at four stations were analyzed. The standard deviation and correlation coefficient of the statistical indicators by the models over the stations are

457 listed in Fig.5. It was clear that GEM5 models at different stations have the lowest 458 standard deviation, the lowest mean square error and the highest correlation 459 coefficient with the standard values. These results further confirmed the performance 460 of GEM5 at different stations in Northeast China.

461 The results of this study showed that the models with complete inputs had the 462 highest accuracy. This indicated that the effect of each meteorological factor on $R_{\mathrm{s}}$ 463 estimation was positive. However, the models with $T_{\max }$ and $T_{\min }$ as inputs showed 464 lower accuracy, especially the HS and BC models. The models considering $n$ (input 465 scenarios 3, 4, and 5) showed a much higher accuracy, which revealed that $n$ is the 466 most important factor affecting $R_{\mathrm{s}}$ estimation in Northeast China. Mecibah et al. (2014)

467 investigated the performance of different $R_{\mathrm{s}}$ models and found that the accuracy of 468 models with $n$ was much higher than that of models with air temperature. The same 469 conclusion was also reported by Zhang et al. (2018) because the magnitude of $n$ 470 directly affects the $R_{\mathrm{s}}$ reaching the surface of the earth.

\section{4. Conclusions}

472 Five machine models with five groups of input parameters and two empirical models 473 were evaluated for $R_{\mathrm{s}}$ prediction using meteorological data from four stations in 474 Northeast China. The GEM with full climatic data as inputs showed the highest 
475

accuracy with RMSE, RRMSE, MAE, and $E_{n s}$ values of $1.416 \mathrm{MJ} \cdot \mathrm{m}^{-2} \cdot \mathrm{d}^{-1}, 10.27 \%$, $1.018 \mathrm{MJ} \cdot \mathrm{m}^{-2} \cdot \mathrm{d}^{-1}$, and 0.962 , respectively. The BT model showed a worse performance with full climatic data as inputs, but showed better performance under other input scenarios compared with that of the GEM. $n$ is the most influential factor affecting $R_{\mathrm{s}}$ estimation by machine learning models.

Overall, the GEM5 is recommended for estimating $R_{\mathrm{s}}$ in Northeast China when all the meteorological variables are available. The BT3 model is recommended when only $n$ and air temperature data are accessible. The BT4 model and GEM4 are recommended only when sunshine data and $P$ data are available.

\section{Acknowledgments}

We wish to thank the China Meteorological Administration for providing the data for this study. This study was supported by the Scientific Research Program of Higher Education in Hebei Province (QN2021227) and the Water Conservancy Research and Extension Project of Hebei Province(2020-64) and the Hebei Province Innovation Ability Promotion Plan, Soft Science Research(20557682D) and the Colleges and Universities in Hebei Province Science and Technology Research(ZD2020348) and the Doctoral Scientific Research Foundation of Hebei University of Water Resources and Electric Engineering(SYBJ1902)

\section{References}

Allen, R., 1995. Evaluation of Procedures of Estimating Mean Monthly Solar Radiation from Air 
Anis, M. S., Jamil, B., Ansari, M.A., Bellos, E., 2019. Generalized models for estimation of global solar radiation based on sunshine duration and detailed comparison with the existing: A case study for India. Sustainable Energy Technologies and Assessments, 31, 179-198.

Annandale, J., Jovanovic, N., Benade, N., Allen, R., 2002. Sofware for missing data error analysis of Penman-Monteith reference evapotranspiration. Irrigation Science 21(2), 57-67. estimation methods using ANN and empirical models. Computers and Electronics in Agriculture $160,160-167$.

Bailek. N., Bouchouicha, K., Al-Mostafa, Z., El-Shimy, M., Aoun, N., Slimani, A., Al-Shehri, S., 2018. A new empirical model for forecasting the diffuse solar radiation over Sahara in the Algerian Big South. Renewable Energy 117, 530-537.

Belaid, A., Mellit, A., Prediction of daily and mean monthly global solar radiation using support vector machine in an arid climate, Energy Convers Manag 118, 105-118.

Besharat, F., Dehghan, A. A., Faghih, A. R., 2013. Empirical models for estimating global solar radiation: A review and case study. Renewable and Sustainable Energy Reviews 21, 798-821. maximum and minimum temperature. Agricultural and Forest Meteorology 31(2), 159-166.

514 Bueno, C. L., Mateo., C. C., Justo., J. S., Sanz., S. S., 2019. Machine learning regressors for solar 
Buja, A., Swayne, D. F., Littman, M. L., Dean, N., Hofmann, H., Chen, L., 2008. Data visualization with multidimensional scaling. Journal of Computational and Graphical Statistics 17(2), 444-472.

Chen, J.L., Liu, H.B., Wu, W., Xie, D.T., 2011. Estimation of monthly solar radiation from measured temperatures using support vector machines - a case study. Renew. Energy 36, 413-420

Chen, Q. Y., Ding, Q., Liu, X. H., 2019. Establishment and validation of a solar radiation model for a living wall system. Energy \& Buildings 195, 105-115. radiation in Africa. Renew Sustain Energy Rev 78, 955-95.

Citakoglu, H., 2015. Comparison of artificial intelligence techniques via empirical equations for prediction of solar radiation. Computers and Electronics in Agriculture 118, 28-37.

Desideri, U., Zepparelli, F., Morettini, V., Garroni, E., 2013. Comparative analysis of concentrating $102,765-784$.

Demircan, C., Bayrakçı, H.C., Keçebaş, A., 2020. Machine learning-based improvement of empiric models for an accurate estimating process of global solar radiation. Sustainable Energy reference conditions for river bioassessment by incorporating boosted trees in the environmental 
538 Fan, J., Wang, X., Wu, L., Zhou, H., Zhang, F., Yu, X., Lu, X., Xiang, Y., 2018. Comparison of support vector machine and extreme gradient Boosting for predicting daily global solar radiation using temperature and precipitation in humid subtropical climates: a case study in China. Energy Convers Manag 164, 102-111.

Fan, J. L., Wu, L. F., Zhang, F. C., Cai, H. J., Zeng, W. Z., Wang, X. K., Zou, H. Y., 2019. Empirical and machine learning models for predicting daily global solar radiation from sunshine duration: A review and case study in China. Renewable and Sustainable Energy Reviews 100, 186-212.

Feng, Y., Cui N. B., Gong D. Z., Zhang Q. W, Zhao L., 2017a. Evaluation of random forests and generalized regression neural networks for daily reference evapotranspiration modeling,

Feng, Y., Jia, Y., Cui, N., Zhao, L., Li, C., Gong, D., 2017b. Calibration of Hargreaves model for reference evapotranspiration estimation in Sichuan basin of southwest China. Agriculture Water

Feng, Y., Jia, Y., Zhang, Q., Gong, D., Cui, N., 2018. National-scale assessment of pan evaporation models across different climatic zones of China. Journal of Hydrology 564, 314-328.

Feng, Y., Cui, N., Chen, Y., Gong, D., Hu, X. 2019a. Development of data-driven models for prediction of daily global horizontal irradiance in northwest China. Journal of Cleaner Production 223, 136-

556 Feng, Y., Cui, N., Hao, W., Gao, L. and Gong, D., 2019b. Estimation of soil temperature from meteorological data using different machine learning models. Geoderma 338, 67-77. 
Gueymard, C. A., 2001. Parameterized transmittance model for direct beam and circumsolar spectral irradiance. Sol Energy 71, 325-346.

Hargreaves, G. H., Samani, Z. A., 1982. Estimating potential evapotranspiration. Journal of the Irrigation \& Drainage Division, 108(3), 225-230. temperature-based models for predicting global solar radiation. Applied Energy 179, 437-450.

Hossain, M., Mekhilef, S., Olatomiwa, L., Danesh, M., Shamshirband, S., 2017. Application of Extreme Learning Machine for short term output power forecasting of three grid-connected PV

Israeli, A., Rokach, L., Shabtai, A., 2019. Constraint learning-based gradient boosting trees. Expert Systems With Applications 128, 287-300.

Jamil, B., Akhtar, N., 2017. Estimation of diffuse solar radiation in the humid-subtropical climatic systems. Journal of Cleaner Production 167, 395-405.

Jamil, B., Siddiqui, A.T., 2018. Estimation of monthly mean diffuse solar radiation over India: performance of two variable models under different climatic zones. Sustainable Energy Technologies and Assessments, 25, 161-180. 
Jin, Z., Ye, Z. W., Gang Y., 2005. General formula for estimation of monthly average daily global solar radiation in China. Energy Conversion and Management 46(2), 257-268.

Kaba, K., Sarıül, S., Avcı, M., Kandırmaz, M., 2018. Estimation of daily global solar radiation using deep learning model. Energy 162, 126-135.

Katiyar, A. K., Pandey, C. K., 2010. Simple correlation for estimating the global solar radiation on horizontal surfaces in India. Energy 35(12), 5043-5048.

Khatib, T., Mohamed, A., Sopian, K., 2012. A review of solar energy modeling techniques. Renew Sustain Energy Rev 16, 2864-2869.

Kisi, O., Sanikhani, H., Zounemat-Kermani, M., Niazi, F., 2015. Long-term monthly evapotranspiration modeling by several data-driven methods without climatic data. Computers and Electronics in Agriculture. 115, 66-77.

Kisi, O., 2016. Modeling reference evapotranspiration using three different heuristic regression approaches. Agric. Water Manage. 169, 162-172.

Lesser, B., Mucke, M., Gansterer, W. W., 2011. Effects of Reduced Precision on Floating-Point SVM Classification Accuracy. Procedia Computer Science 4, 508-517.

Liu, X., Mei, X., Li, Y., Wang, Q., Jensen, J. R., Zhang, Y., Porter, J. R., 2009. Evaluation of temperature-based global solar radiation models in China. Agric For Meteorol 149, 1433-1446.

Liu, C., Zheng, D., Zhao, L., Liu, C., 2014. Gaussian fitting for carotid and radial artery pressure waveforms: Comparison between normal subjects and heart failure patients. Bio-Medical Materials and Engineering 24, 271-277.

Liu., Y, Zhou., Y, Wang., D, Wan., Y, Li., Y, Zhu., Y, 2017. Classification of solar radiation zones and 

distribution for shortwave atmospheric radiative transfer. Journal of the Atmospheric Sciences 61, $2588-2601$.

611 Pan, T., Wu, S. H., Dai, E. F., Liu, Y.J., 2013. Estimating the daily global solar radiation spatial distribution from diurnal temperature ranges over the Tibetan Plateau in China. Appl Energy 107, 384-393.

614 Persson, G., Bacher, P., Shiga, T., Madsen, H., 2017. Multi-site solar power forecasting using gradient boosted regression trees. Solar Energy 120, 423-436.

616 Qiu R J, Wang Y K, Wang D, Qiu W J, Wu J C, Tao W Y, 2020. Water temperature forecasting based on modified artificial neural network methods: Two cases of the Yangtze River. Science of the Total Environment, 737, 1-12.

619 Quej, V. H., Almorox, J., Arnaldo, J. A., Saito, L., 2017. ANFIS, SVM and ANN soft-computing 620 techniques to estimate daily global solar radiation in a warm sub-humid environment. Journal of 
622 Quinlan, J. R., 1992. Learning with continuous classes, in Proceedings of the 5th Australian Joint Conference on Artificial Intelligence, 343-348.

Sattari, M. T., Pal, M., Apaydin, H., et al, 2013. M5 model tree application in Daily River flow forecasting in Sohu Stream, Turkey. Water Resources, 40(3), 233-242. SVM-FFA method for prediction of monthly mean global solar radiation. Theoretical and Applied Climatology 125, 53-65. Comparison of heuristic and empirical approaches for estimating reference evapotranspiration from limited inputs in Iran. Computers and Electronics in Agriculture. 108, 230-241. for reference evapotranspiration modeling using limited climatic data in a semi-arid highland environment. Journal of Hydrology. 44, 78-89.

635 Tian, H., Zhao, Y. Q., Luo, M., He Q. Q., Han, Y., Zeng, Z. L., 2020. Estimating PM2.5 from multisource data: A comparison of different machine learning models in the Pearl River Delta of

638 Vapink, V., 1999. The nature of statistical learning theory[M]. New York: Springer-Verlag.

639 Wang, Y., Witten, I. H., 1997. Inducing model trees for continuous classes, In Proceedings of the ninth European conference on machine learning, 128-137.

641 Wang, L., Kisi, O., Zounemat-Kermani, M., Salazar, G.A., Zhu, Z., Gong, W., 2016. Solar radiation 
Wild, M., Gilgen, H., Roesch, A., Ohmura, A., Long, C. N., Dutton, E. G., Forgan, B., Kallis, A., Earth's surface. Sci 308(5723), 847-850. extension of Arps decline model and gradient boosting with categorical features support for predicting daily global solar radiation in humid regions, Energy Convers Manag 183, 280-295. greenhouse based on LSSVM optimized by improved PSO. Computers and Electronics in Solar Radiation Models in Different Regions of China. Advances in Meteorology 2018, 1-21. Estimation and validation of daily global solar radiation by day of the year-based models for Levels and distribution of synthetic musks in farmland soils from the Three Northeast Provinces

661 Zhu, S.L., Heddam, S., Nyarko, E.K., Hadzima-Nyarko, M., Piccolroaz, S., Wu, S.Q., 2019a. 
663 systems and artificial neural networks models. Environmental Sciences and Pollution Research. 26,

$664 \quad 402-420$.

665 Zhu, S.L., Nyarko, E.K., Hadzima-Nyarko, M., Heddam, S., Wu, S.Q., 2019b. Assessing the

666 performance of a suite of machine learning models for daily river water temperature prediction.

$667 \quad$ PeerJ 7, e7065.

668 Zou, L., Wang, L., Xia, L., Lin, A., Hu, B., Zhu, H., 2017. Prediction and comparison of solar radiation

669 using improved empirical models and adaptive neuro-fuzzy inference systems. Renew Energy 106,

670 343-353.

671 
Table 1 Climatic conditions of the four stations in this study.

\begin{tabular}{|c|c|c|c|c|c|c|c|c|}
\hline Station & Longitude $\left({ }^{\circ} \mathrm{E}\right)$ & Latitude $\left({ }^{\circ} \mathrm{N}\right)$ & Variable & $\operatorname{Max}$ & Min & Average & $S_{x}$ & $\mathrm{C}_{\mathrm{v}}$ \\
\hline \multirow[t]{6}{*}{ Harbin } & 126.8 & 45.8 & $U_{2}\left(\mathrm{~m} \cdot \mathrm{s}^{-1}\right)$ & 7.6 & 0.0 & 1.9 & 0.9 & 0.5 \\
\hline & & & $T_{\text {ave }}\left({ }^{\circ} \mathrm{C}\right)$ & 30.9 & -30.9 & 5.3 & 15.1 & 2.8 \\
\hline & & & $n(\mathrm{~h})$ & 14.9 & 0.0 & 6.3 & 4.0 & 0.6 \\
\hline & & & $H_{\mathrm{r}}(\%)$ & 100 & 20 & 60 & 20 & 20 \\
\hline & & & $P\left(\mathrm{~mm} \cdot \mathrm{d}^{-1}\right)$ & 146.6 & 0.0 & 1.4 & 5.4 & 3.7 \\
\hline & & & $R_{\mathrm{s}}\left(\mathrm{MJ} \cdot \mathrm{m}^{-2} \cdot \mathrm{d}^{-1}\right)$ & 33.3 & 0.0 & 13.0 & 7.2 & 0.6 \\
\hline \multirow[t]{6}{*}{ Jilin } & 125.2 & 43.9 & $U_{2}\left(\mathrm{~m} \cdot \mathrm{s}^{-1}\right)$ & 10.5 & 0.0 & 2.4 & 1.2 & 0.5 \\
\hline & & & $T_{\text {ave }}\left({ }^{\circ} \mathrm{C}\right)$ & 30.4 & -30.1 & 6.5 & 14.2 & 2.2 \\
\hline & & & $n(\mathrm{~h})$ & 14.3 & 0.0 & 7.1 & 3.8 & 0.5 \\
\hline & & & $H_{\mathrm{r}}(\%)$ & 100 & 10 & 60 & 20 & 30 \\
\hline & & & $P\left(\mathrm{~mm} \cdot \mathrm{d}^{-1}\right)$ & 122.0 & 0.0 & 1.6 & 6.1 & 3.8 \\
\hline & & & $R_{\mathrm{S}}\left(\mathrm{MJ} \cdot \mathrm{m}^{-2} \cdot \mathrm{d}^{-1}\right)$ & 39.6 & 0.0 & 13.5 & 7.4 & 0.5 \\
\hline \multirow[t]{6}{*}{ Shenyang } & 123.5 & 41.7 & $U_{2}\left(\mathrm{~m} \cdot \mathrm{s}^{-1}\right)$ & 9.0 & 0.0 & 2.0 & 1.0 & 0.5 \\
\hline & & & $T_{\text {ave }}\left({ }^{\circ} \mathrm{C}\right)$ & 30.5 & -26.8 & 8.6 & 13.3 & 1.5 \\
\hline & & & $n(\mathrm{~h})$ & 13.9 & 0.0 & 6.5 & 3.9 & 0.6 \\
\hline & & & $H_{\mathrm{r}}(\%)$ & 100 & 10 & 60 & 20 & 30 \\
\hline & & & $P\left(\mathrm{~mm} \cdot \mathrm{d}^{-1}\right)$ & 145.7 & 0.0 & 1.9 & 7.6 & 4.0 \\
\hline & & & $R_{\mathrm{s}}\left(\mathrm{MJ} \cdot \mathrm{m}^{-2} \cdot \mathrm{d}^{-1}\right)$ & 33.4 & 0.0 & 13.5 & 7.0 & 0.5 \\
\hline \multirow[t]{6}{*}{ Yanji } & 129.5 & 42.9 & $U_{2}\left(\mathrm{~m} \cdot \mathrm{s}^{-1}\right)$ & 10.0 & 0.0 & 1.9 & 1.3 & 0.7 \\
\hline & & & $T_{\text {ave }}\left({ }^{\circ} \mathrm{C}\right)$ & 29.7 & -23.7 & 6.0 & 12.8 & 2.1 \\
\hline & & & $n(\mathrm{~h})$ & 14.0 & 0.0 & 6.3 & 3.7 & 0.6 \\
\hline & & & $H_{\mathrm{r}}(\%)$ & 100 & 10 & 60 & 20 & 30 \\
\hline & & & $P\left(\mathrm{~mm} \cdot \mathrm{d}^{-1}\right)$ & 124.6 & 0.0 & 1.5 & 5.5 & 3.6 \\
\hline & & & $R_{\mathrm{s}}\left(\mathrm{MJ} \cdot \mathrm{m}^{-2} \cdot \mathrm{d}^{-1}\right)$ & 32.6 & 0.0 & 13.2 & 6.9 & 0.5 \\
\hline
\end{tabular}


Table 2 Input combinations for training the machine learning models in this study.

\begin{tabular}{|c|c|c|c|c|c|c|c|c|c|c|c|}
\hline \multirow{2}{*}{$\begin{array}{c}\text { Input } \\
\text { scenario }\end{array}$} & \multirow{2}{*}{$\begin{array}{c}\text { Model } \\
\text { ID }\end{array}$} & \multirow{2}{*}{$\frac{\text { Models }}{\text { M5T }}$} & \multirow{2}{*}{ Model ID } & \multirow{2}{*}{$\frac{\text { Models }}{\text { SVM }}$} & \multirow{2}{*}{ Model ID } & \multirow{2}{*}{$\frac{\text { Models }}{\text { GEM }}$} & \multirow{2}{*}{ Model ID } & \multirow{2}{*}{$\frac{\text { Models }}{\text { RF }}$} & \multirow{2}{*}{-Model ID - } & \multirow{2}{*}{$\frac{\text { Models }}{\text { BT }}$} & \multirow{2}{*}{ Inputs } \\
\hline & & & & & & & & & & & \\
\hline 1 & A & M5T1 & $\mathrm{E}$ & SVM1 & $\mathrm{K}$ & GEM1 & $\mathrm{P}$ & RF1 & $\mathrm{U}$ & BT1 & $\mathrm{DOY}, R_{\mathrm{a}}$ \\
\hline 2 & $\mathrm{~B}$ & M5T2 & G & SVM2 & $\mathrm{L}$ & GEM2 & Q & RF2 & $\mathrm{V}$ & BT2 & $\mathrm{DOY}, R_{\mathrm{a}}, T_{\max }, T_{\min }$ \\
\hline 3 & $\mathrm{C}$ & M5T3 & $\mathrm{H}$ & SVM3 & M & GEM3 & $\mathrm{R}$ & RF3 & $\mathrm{W}$ & BT3 & $\mathrm{DOY}, R_{\mathrm{a}}, T_{\max }, T_{\min }, n$ \\
\hline 4 & $\mathrm{D}$ & M5T4 & I & SVM4 & $\mathrm{N}$ & GEM4 & $\mathrm{S}$ & RF4 & $\mathrm{X}$ & BT4 & $\mathrm{DOY}, R_{\mathrm{a},} n, \ln (P+1)$ \\
\hline 5 & $\mathrm{E}$ & M5T5 & $\mathrm{J}$ & SVM5 & $\mathrm{O}$ & GEM5 & $\mathrm{T}$ & RF5 & $\mathrm{Y}$ & BT5 & $\mathrm{DOY}, R_{\mathrm{a}}, T_{\max }, T_{\min }, n, H_{\mathrm{r}}, \ln (P+1)$ \\
\hline
\end{tabular}


676 Table 3 Parameters applied for different machine learning models in this study.

\begin{tabular}{cc}
\hline Model & Key parameters \\
\hline M5T model & Minimum leaf size $=10$, Minimum parent size $=20$ \\
SVM & Kernel function type $=$ Gaussian function, Gamma $=30$, Cost $=40$ \\
RF model & Maximum depth of the tree $=3$, Number of trees $=500$ \\
GEM & Kernel function type $=$ Gaussian function, Gamma $=2$, Cost $=10$ \\
BT model & Size of regressions trees $=6$, Number of iterations $=200$ \\
\hline
\end{tabular}


Table 4 Statistical performances of daily $R_{\mathrm{s}}$ of different models at the four stations. The best model in each station is marked in bold.

\begin{tabular}{|c|c|c|c|c|c|c|c|c|c|c|c|c|c|c|c|c|c|c|c|c|c|c|c|c|c|c|c|c|}
\hline Station & Indicat & $5 \mathrm{~T} 1$ & M5T2 & M5T3 & M5T4 & M5T5 & SVM1 & SVM2 & SVM3 & SVM4 & SVM5 & GEM1 & GEM2 & GEM3 & GEM4 & GEM5 & $\mathrm{RF} 1$ & RF2 & RF3 & RF4 & RF5 & BT1 & BT2 & BT3 & BT4 & $3 \mathrm{~T} 5$ & HS & $\mathrm{BC}$ \\
\hline \multirow[t]{4}{*}{ Harbin } & $\operatorname{MSE}\left(\mathrm{MJ} \cdot \mathrm{m}^{-}\right.$ & 5.207 & 4.132 & 2.900 & 2.809 & 2.824 & 5.749 & 3.791 & 2.518 & 2.497 & 2.406 & 5.049 & 3.398 & 49 & 2.161 & 1.719 & 5.404 & 4.044 & 2.813 & 2.766 & 2.700 & 2.893 & 3.068 & 1.944 & 2.033 & 1.797 & 4.229 & 4.127 \\
\hline & RRMSE (\%) & 38.4 & 30.5 & 4 & 17 & 20.8 & 41.4 & 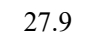 & 3.6 & 4 & 17.7 & 2 & 0 & 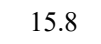 & 9 & 12.7 & 9.8 & 9.8 & 20.7 & 20.4 & 9.9 & 36.1 & 2.6 & 5.4 & 15.0 & 3.2 & 31.2 & 30.4 \\
\hline & $E_{n s}$ & 505 & 8 & 847 & 0.856 & 0.854 & 39 & 738 & 0.884 & 0.886 & 0.894 & 535 & 0.789 & .916 & 915 & 0.946 & 0.467 & 0.702 & 0.856 & 0.860 & 0.867 & 0.563 & 0.828 & 0.931 & 0.925 & 0.941 & 0.674 & +0.689 \\
\hline & $\operatorname{MAE}(\mathrm{MJ} \cdot \mathrm{m}$ & 4.015 & 3.096 & 2.237 & 2.164 & 2.187 & 4.718 & 2.791 & 1.892 & 1.869 & 1.798 & 3.886 & 2.524 & 1.604 & 1.632 & 1.283 & 4.110 & 3.067 & 2.178 & 2.149 & 2.108 & 3.742 & 2.305 & 1.456 & 1.525 & 1.353 & 3.270 & 3.187 \\
\hline \multirow{4}{*}{ Jilin } & RRMSE (\%) & 40.7 & 32.8 & 15.1 & 14.6 & 14.4 & 146.1 & 28.9 & 13.5 & 13.4 & 12.9 & 40.8 & 5.5 & 11.8 & 11.3 & 9.1 & 44.2 & 30.2 & 14.3 & 14.5 & 13.7 & 43.6 & 23.2 & 11.1 & 11.3 & 10.4 & 32.2 & 30.9 \\
\hline & $R^{2}$ & 0.474 & 0.661 & 0.929 & 0.934 & 0.933 & 0.147 & 0.734 & 0.942 & 0.943 & 0.947 & 0.473 & 0.795 & 0.956 & 0.960 & 0.974 & 0.384 & 0.712 & 0.935 & 0.934 & 0.941 & 0.503 & 0.835 & 0.961 & 0.959 & 0.966 & 0.672 & 20.696 \\
\hline & $E_{n s}$ & 2 & 8 & 8 & 33 & 0.934 & 0.105 & 34 & 0.942 & 0.943 & 47 & 471 & 0 & 56 & 959 & 0.973 & 0.378 & 0.711 & 0.935 & 0.933 & 0.940 & 0.501 & 0.829 & 0.961 & 0.959 & 0.966 & 0.671 & 0.696 \\
\hline & $\operatorname{MAE}\left(\mathrm{MJ} \cdot \mathrm{m}^{-2} \cdot \mathrm{d}^{-1}\right)$ & 4.125 & 3.062 & 7 & 1.377 & 1.358 & 15.663 & 2.714 & 1.249 & 1.256 & 1.183 & 17 & 2.403 & 1.077 & 1.067 & 0.844 & 4.462 & 2.888 & 1.337 & 1.392 & 1.271 & 4.030 & 2.211 & 1.013 & 1.072 & 0.945 & 3.248 & 3.069 \\
\hline \multirow[t]{4}{*}{ Shenyang } & $\operatorname{RMSE}\left(\mathrm{MJ} \cdot \mathrm{m}^{-2} \cdot \mathrm{d}^{-1}\right)$ & 5.697 & 4.407 & 2.619 & 2.539 & 2.484 & 5.95 & 3.983 & 2.274 & 2.3 & 2.119 & 5.586 & 3.565 & 2.019 & 2.088 & 1.658 & 5.919 & 4.283 & 2.465 & 2.526 & 2.347 & 5.355 & 3.227 & 1.876 & 2.010 & 1.754 & 4.557 & 4.479 \\
\hline & RRMSE (\%) & 40.1 & 31.0 & 18.4 & 17.9 & 17.5 & 2 & 3.0 & 6.0 & 16.8 & 15.5 & 39.3 & 25.1 & 14.2 & 14.7 & 11.7 & 41.6 & 30.1 & 17.3 & 17.8 & 6.5 & 37.7 & 22.7 & 13.2 & 14.1 & 14.1 & 32.1 & 31.5 \\
\hline & $E_{n s}$ & 0.421 & 0.654 & 0.878 & 0.885 & 0.890 & 0.359 & 0.717 & 0.908 & 0.898 & 0.914 & 0.444 & 0.773 & 0.927 & 0.922 & 0.951 & 0.375 & 0.673 & 0.892 & 0.886 & 0.902 & 0.489 & 0.814 & 0.937 & 0.928 & 0.945 & 0.630 & 0.642 \\
\hline & MAE $(\mathrm{MJ} \cdot \mathrm{n}$ & 4.557 & 3.284 & 1.836 & 1.797 & 1.764 & 4.741 & 2.912 & 1.566 & 1.642 & 4.836 & 4.466 & 2.637 & 1.394 & 1.481 & 1.147 & 4.644 & 3.234 & 1.778 & 1.799 & 1.703 & 4.265 & 2.412 & 1.299 & 1.407 & 1.206 & 3.526 & 3.483 \\
\hline \multirow[t]{5}{*}{ Yanji } & $\operatorname{RMSE}\left(\mathrm{MJ} \cdot \mathrm{m}^{-2} \cdot \mathrm{d}^{-1}\right)$ & 5.402 & 3.849 & 1.746 & 1.675 & 1.743 & 6.879 & 3.454 & 1.509 & 3.521 & 1.434 & 5.209 & 3.118 & 1.274 & 1.319 & 1.045 & 5.571 & 3.767 & 1.686 & 1.671 & 1.682 & 5.030 & 2.809 & 1.226 & 1.259 & 1.149 & 4.063 & 3.885 \\
\hline & RRMSE (\%) & 39.3 & 28.0 & 12.1 & 12.2 & 12.7 & & 25.1 & 1100 & 25.0 & 10.4 & 37.9 & 2.1 & 3 & 9.6 & 7.6 & 40.5 & 27.4 & 12.3 & 12.2 & 12.2 & 36.6 & 20.4 & 8.9 & 9.2 & 8.4 & 29.6 & 28.3 \\
\hline & $R^{2}$ & 0.406 & 0.716 & 0.946 & 0.952 & 0.947 & 0.430 & 0.961 & 0.953 & 0.762 & 0.963 & 0.445 & 0.812 & 0.971 & 0.969 & 0.981 & 0.376 & 0.727 & 0.952 & 0.952 & 0.957 & 0.484 & 0.849 & 0.973 & 0.971 & 0.977 & 0.677 & 0.707 \\
\hline & $E_{n s}$ & 0.396 & 0.693 & 0.937 & 0.942 & 0.937 & 0.021 & 0.753 & 0.959 & 0.744 & 0.958 & 0.439 & 0.799 & 0.966 & 0.964 & 0.977 & 0.358 & 0.706 & 0.941 & 0.942 & 0.941 & 0.476 & 0.837 & 0.969 & 0.967 & 0.973 & 0.659 & 0.688 \\
\hline & $\operatorname{MAE}\left(\mathrm{MJ} \cdot \mathrm{m}^{-2} \cdot \mathrm{d}^{-1}\right)$ & 4.296 & 2.980 & 1.322 & 1.297 & 1.332 & 5.197 & 2.628 & 1.169 & 2.655 & 1.101 & 4.138 & 2.431 & 0.977 & 1.018 & 0.801 & 4.347 & 2.962 & 1.306 & 1.300 & 1.316 & 3.973 & 2.194 & 0.943 & 0.970 & 0.877 & 3.320 & 3.132 \\
\hline
\end{tabular}


Table 5 Statistical performances of monthly $R_{\mathrm{s}}$ of different models at the four stations. The best model in each station is marked in bold.

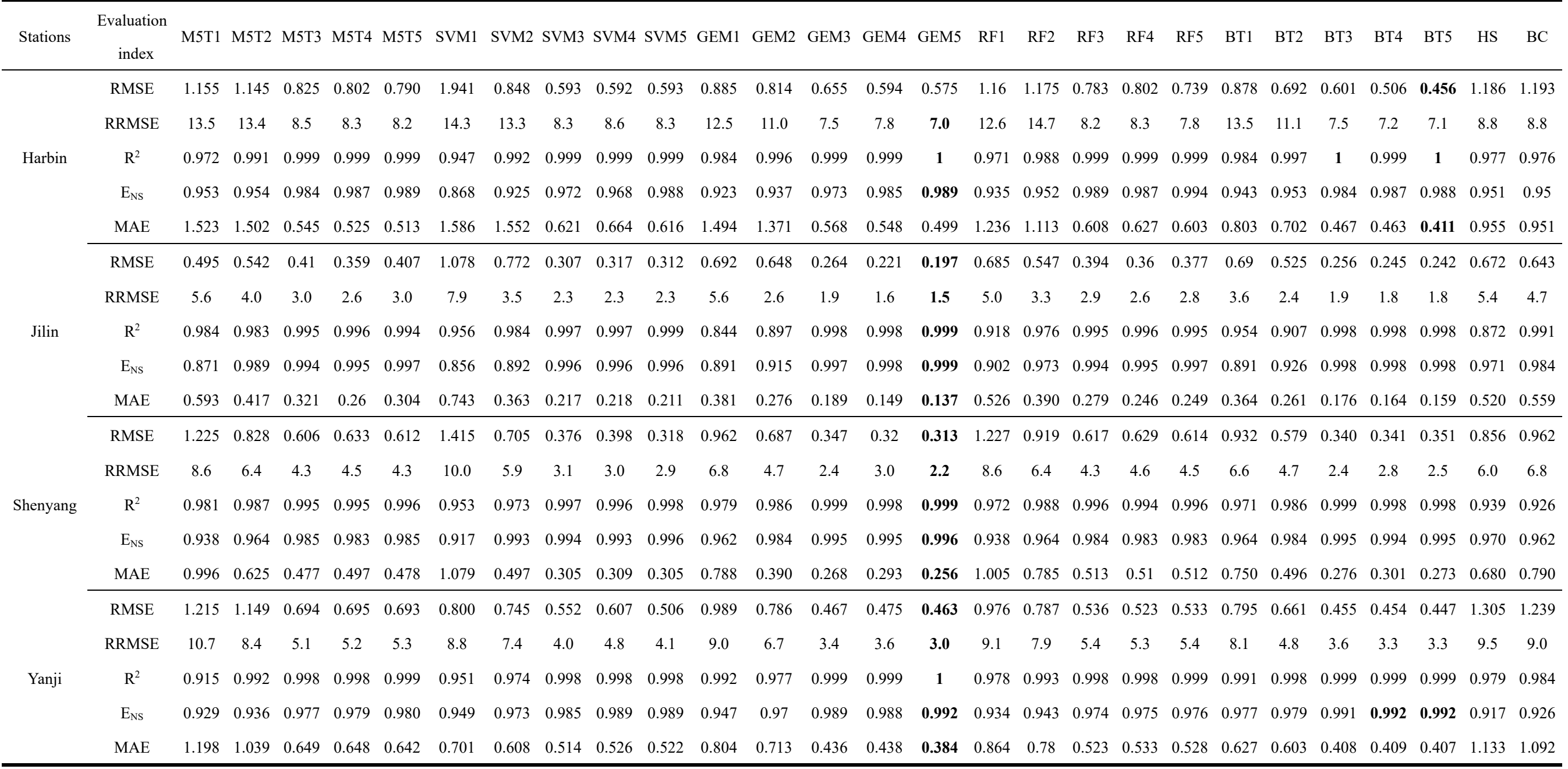




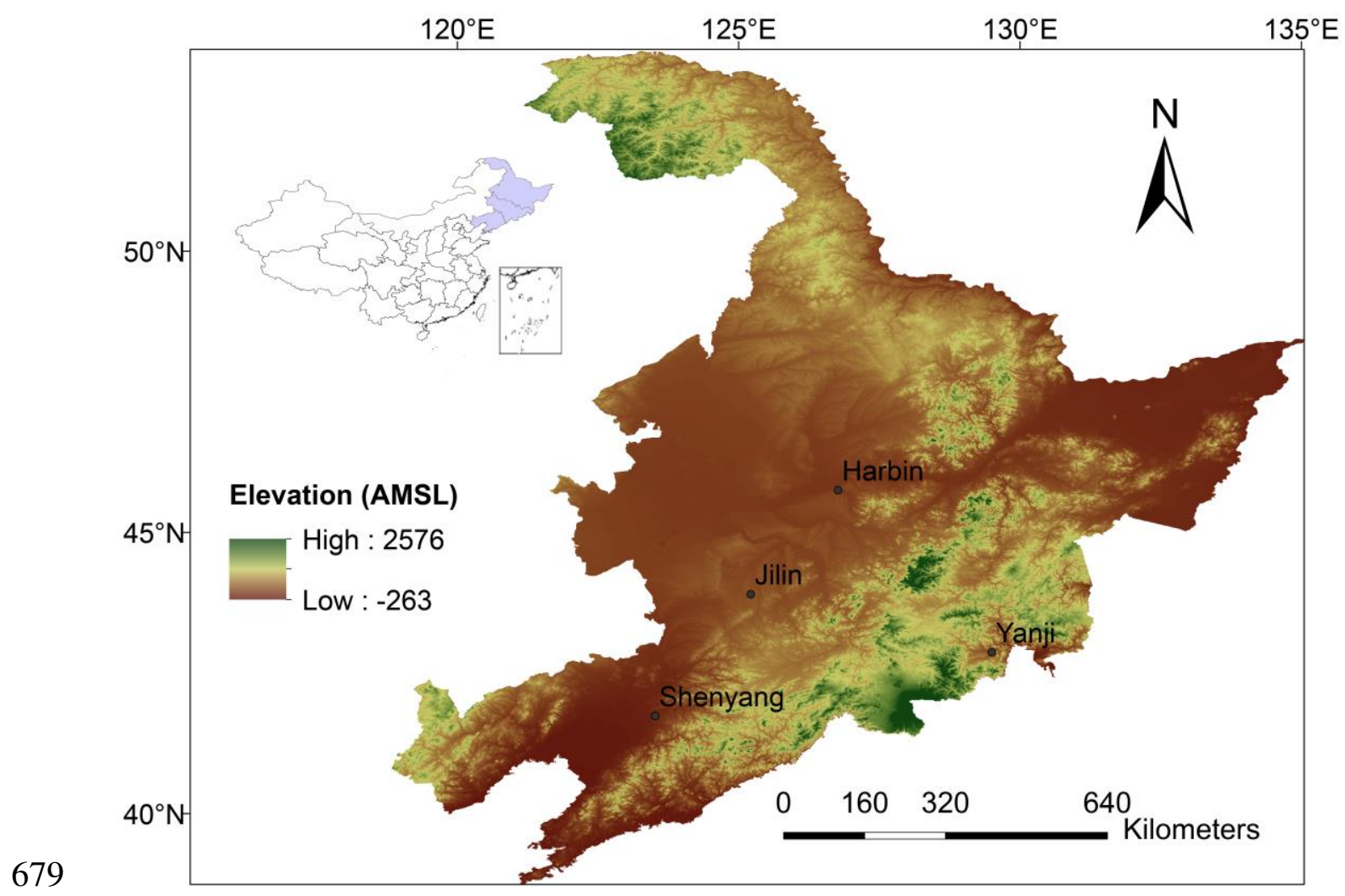

680

Fig. 1 The geographical distribution of the stations in Northeast China. 

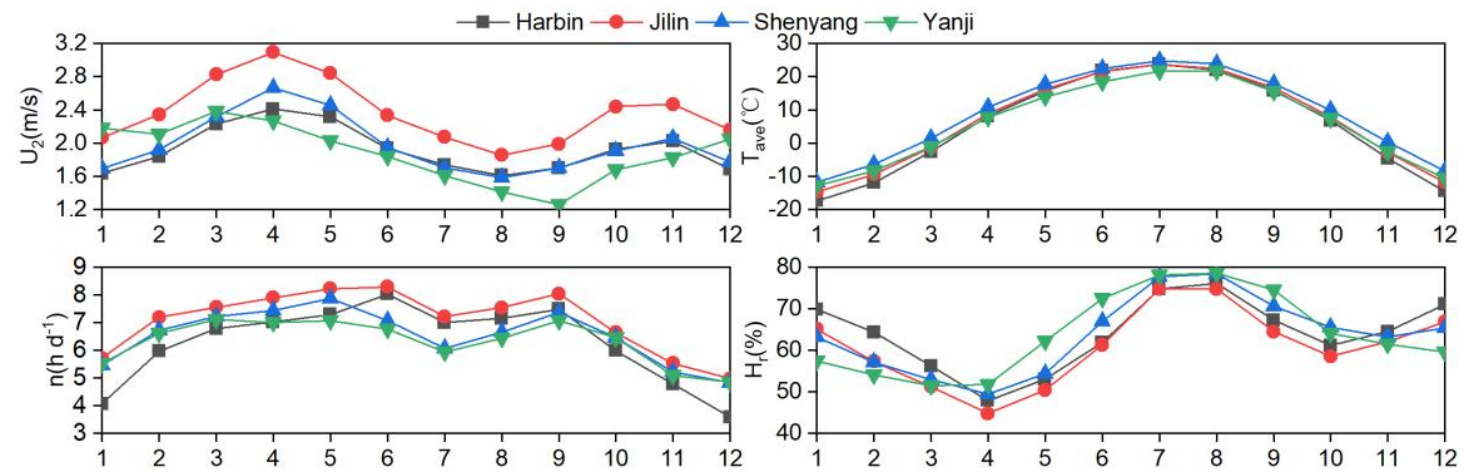

681
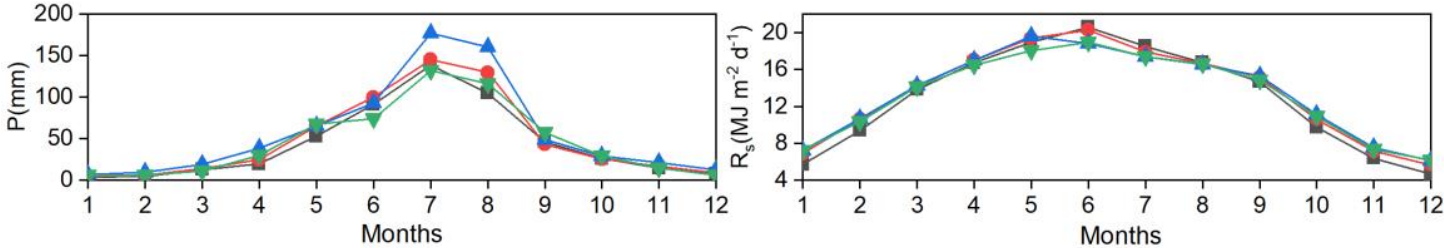

682 Fig.2 Monthly variations of meteorological variables at the four stations in Northeast 683 China. 


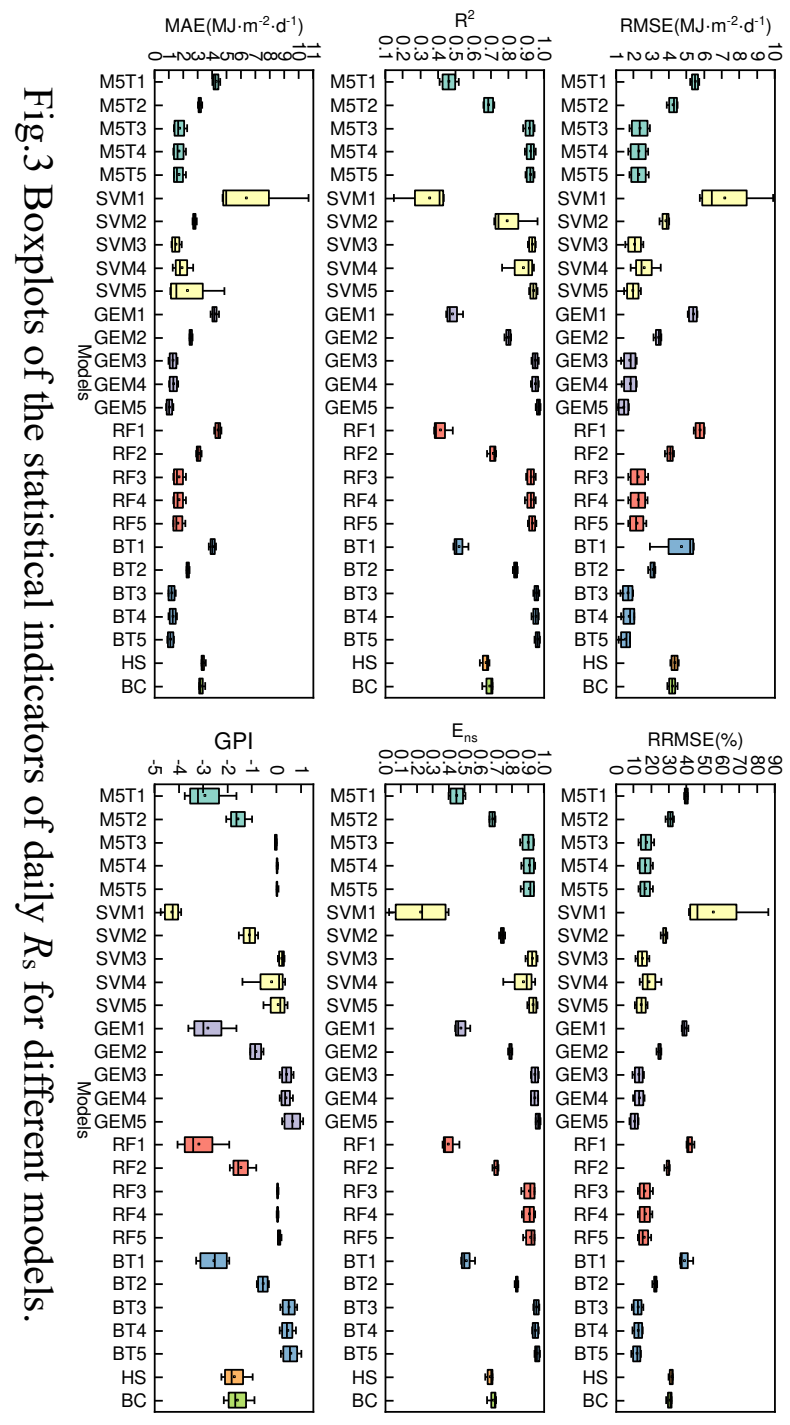




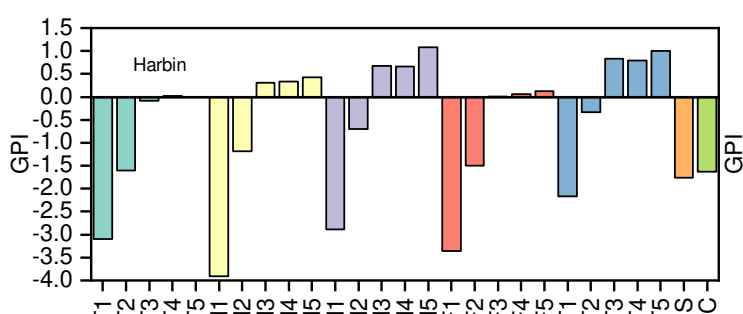

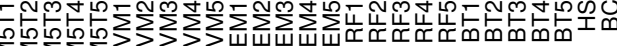

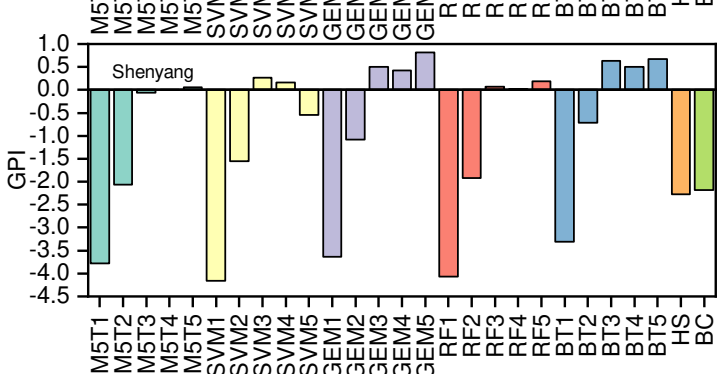

toth Models

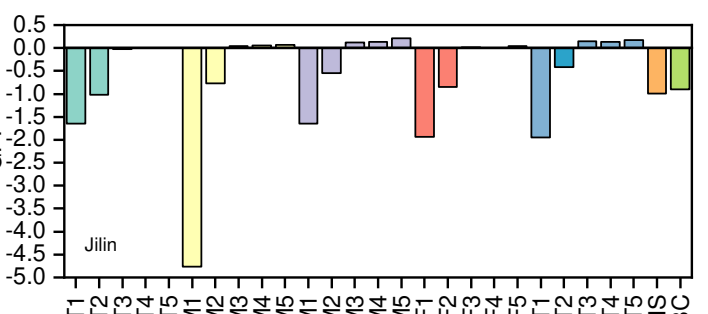

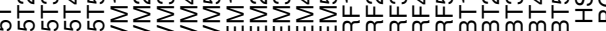

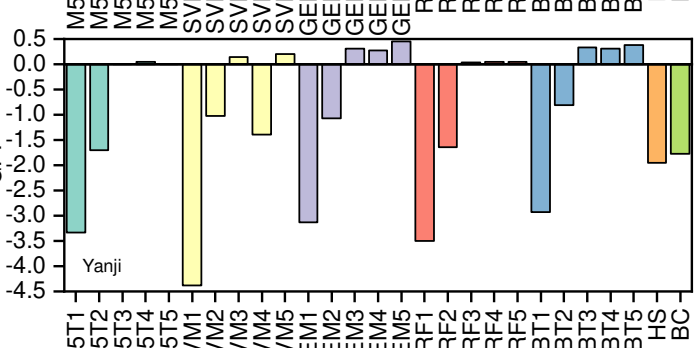

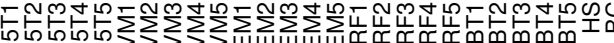
Models
687 688
Fig.4 GPI values of daily $R_{\mathrm{s}}$ of different models at the four stations in Northeast China. 

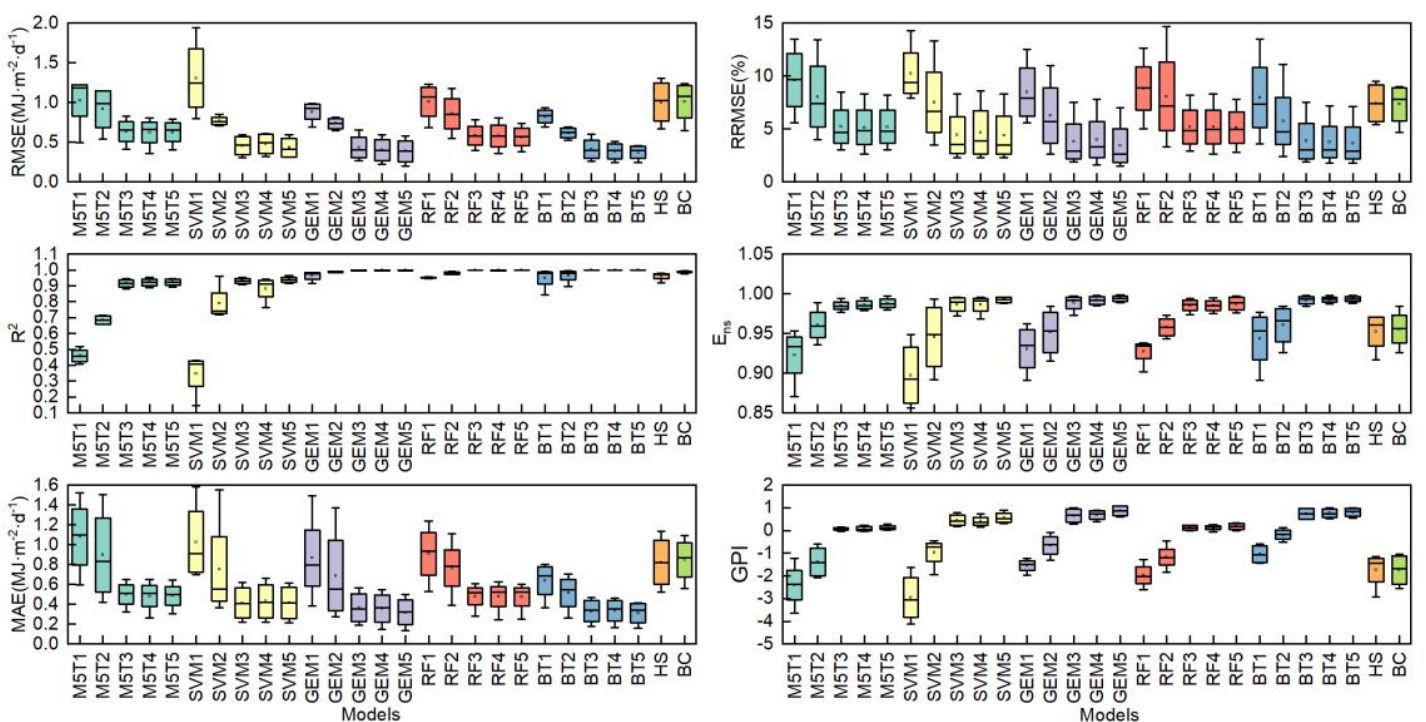

690

Fig.5 Boxplots of the statistical indicators monthly $R_{\mathrm{s}}$ for different models. 

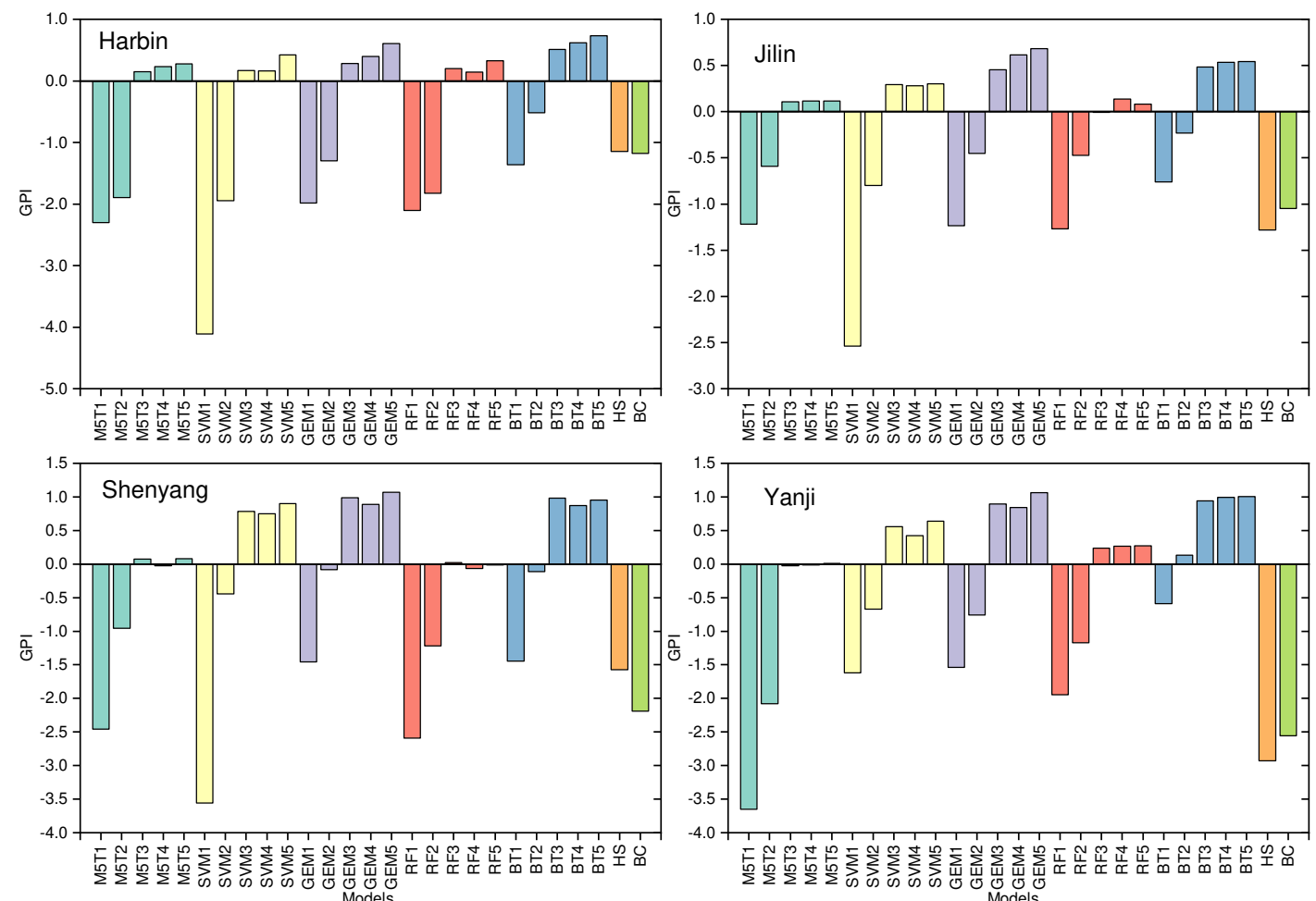

Fig.6 GPI values of monthly $R_{\mathrm{s}}$ of different models at the four stations in Northeast 694 China. 
695

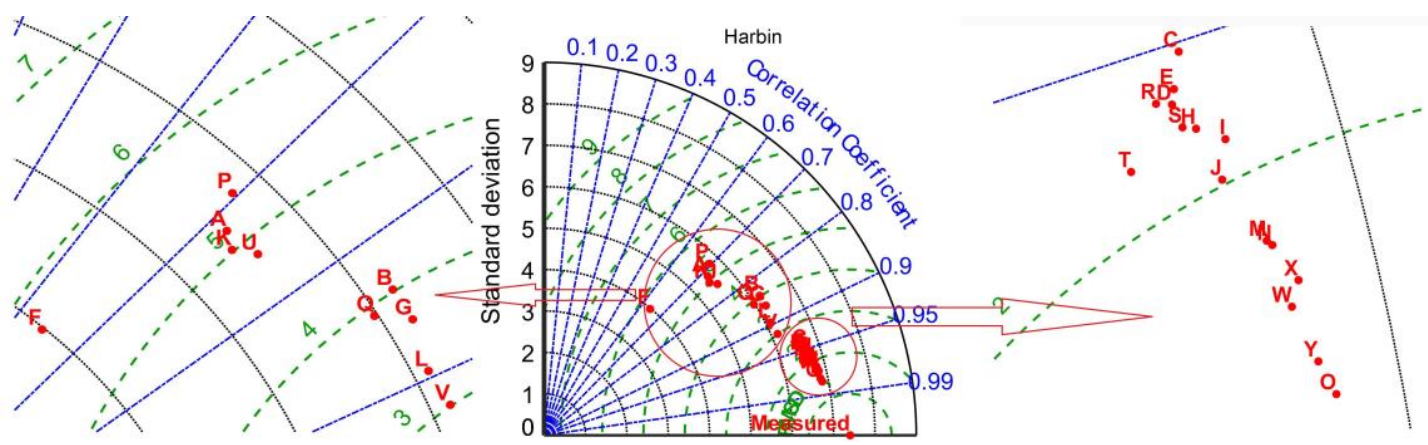

696
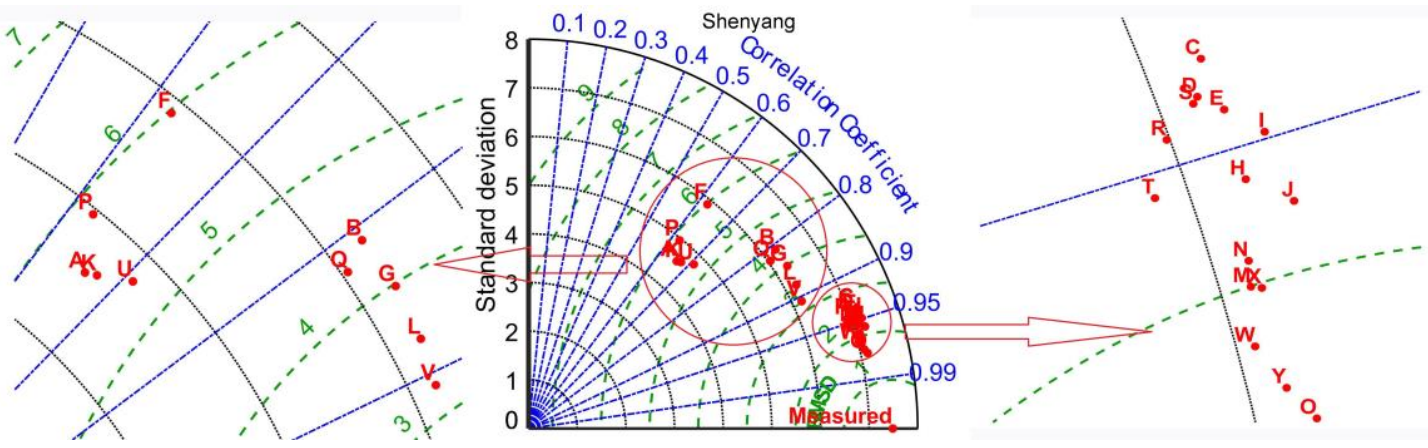

697
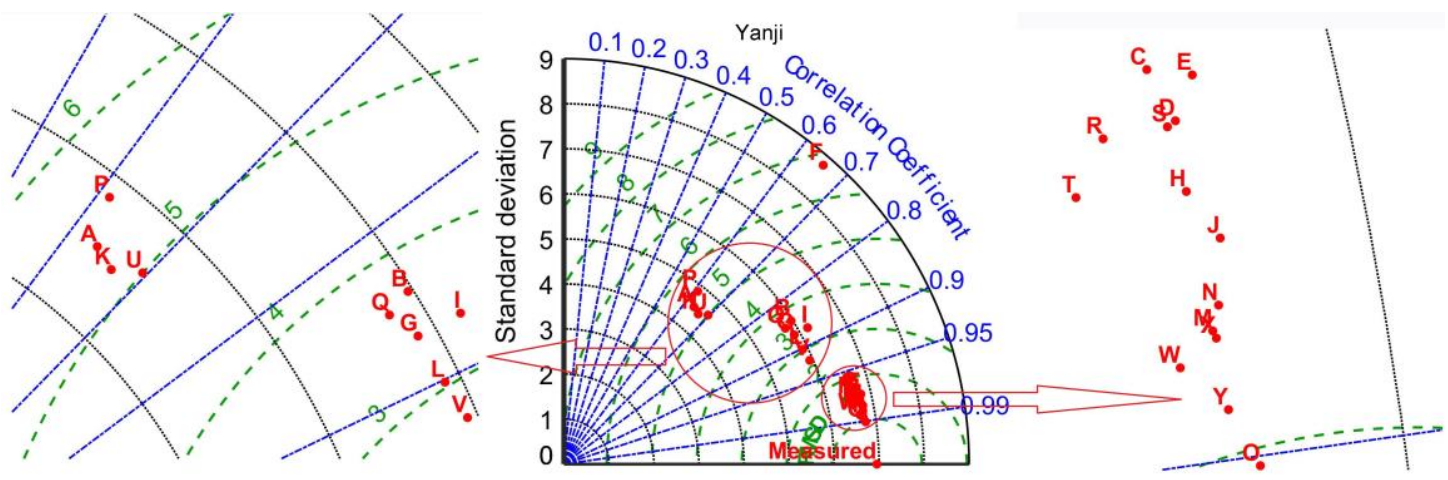

698

Fig.7 Taylor diagrams of daily $R_{\mathrm{s}}$ of different machine learning models at different stations. 


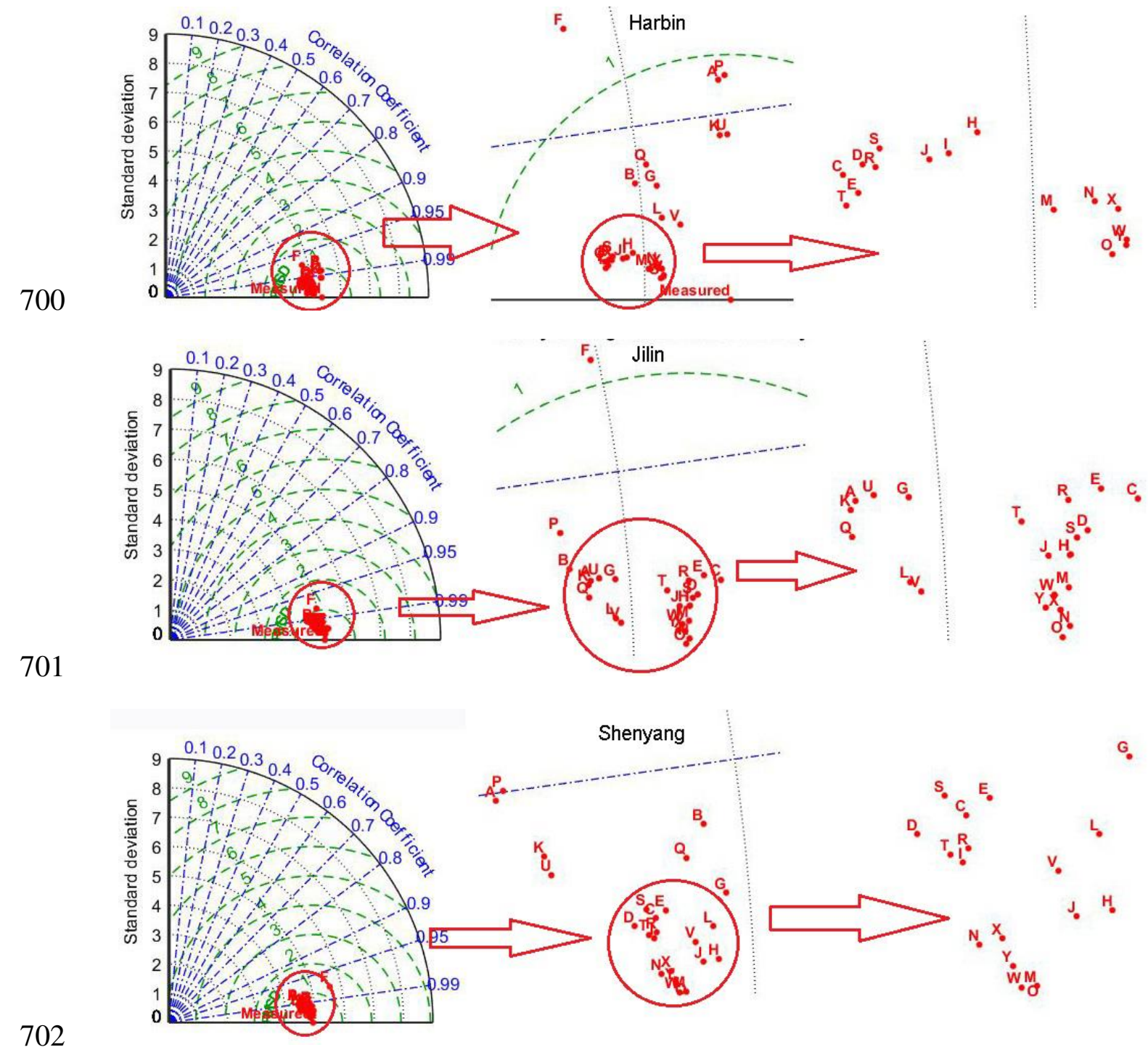

702

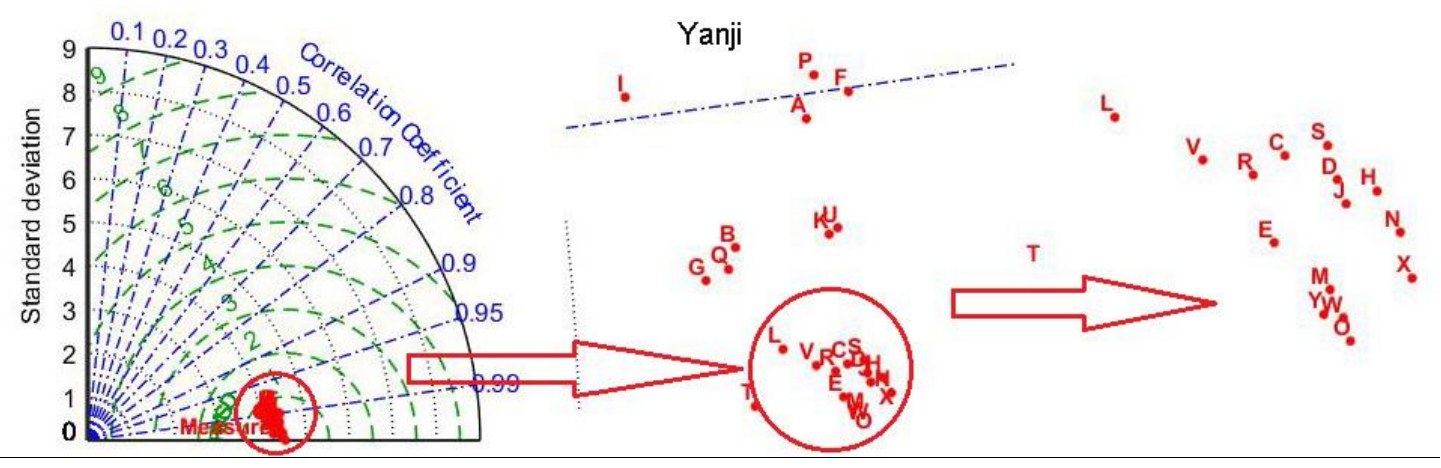

704 Fig.7 Taylor diagrams of monthly $R_{\mathrm{s}}$ of different machine learning models at different 705 stations. 